\title{
Structural and magnetic diversity in alkali-metal manganate chemistry: Evaluating donor and alkali-metal effects in co- complexation processes
}

\author{
Marina Uzelac, ${ }^{[a]}$ Ivana Borilovic, ${ }^{[b]}$ Marco Amores, ${ }^{[a]}$ Thomas Cadenbach, ${ }^{[a],[c]}$ Alan R. Kennedy, ${ }^{[a]}$ \\ Guillem Aromí, ${ }^{[b]}$ and Eva Hevia*[a]
}

\begin{abstract}
By exploring co-complexation reactions between the manganese alkyl $\mathrm{Mn}\left(\mathrm{CH}_{2} \mathrm{SiMe}_{3}\right)_{2}$ and the heavier alkali-metal alkyls $\mathrm{M}\left(\mathrm{CH}_{2} \mathrm{SiMe}_{3}\right)(\mathrm{M}=\mathrm{Na}, \mathrm{K})$ in a benzene/hexane solvent mixture and in some cases adding Lewis donors [bidentate TMEDA, 1,4-dioxane and 1,4-diazabicyclo[2,2,2] octane (DABCO)] has produced a new family of alkali-metal tris(alkyl) manganates. The influences that the alkali-metal and the donor solvent impose on the structures and magnetic properties of these ates have been assessed by a combination of X-ray crystallographic, SQUID magnetization measurements and EPR spectroscopy. These studies uncover a diverse structural chemistry ranging from discrete monomers [(TMEDA $\left.)_{2} \mathrm{MMn}\left(\mathrm{CH}_{2} \mathrm{SiMe}_{3}\right)_{3}\right](\mathrm{M}=\mathrm{Na}, 3 ; \mathrm{M}=\mathrm{K}, 4)$ to dimers $\left[\left\{\mathrm{KMn}\left(\mathrm{CH}_{2} \mathrm{SiMe}_{3}\right)_{3} \cdot \mathrm{C}_{6} \mathrm{H}_{6}\right\}_{2}\right](2)$ and $\left[\left\{\mathrm{NaMn}\left(\mathrm{CH}_{2} \mathrm{SiMe}_{3}\right)_{3}\right\}_{2}(\text { dioxane })_{7}\right]$ (5); and to more complex supramolecular networks $\left[\left\{\mathrm{NaMn}\left(\mathrm{CH}_{2} \mathrm{SiMe}_{3}\right)_{3}\right\}_{\infty}\right](\mathbf{1})$ and $\left.\left[\left\{\mathrm{Na}_{2} \mathrm{Mn}_{2}\left(\mathrm{CH}_{2} \mathrm{SiMe}_{3}\right)_{6}(\mathrm{DABCO})_{2}\right\}_{\infty}\right](\mathbf{7})\right)$ Interestingly, the identity of the alkali-metal exerts a significant effect in the reactions of $\mathbf{1}$ and $\mathbf{2}$ with 1,4-dioxane, as $\mathbf{1}$ produces coordination adduct $\mathbf{5}$, while $\mathbf{2}$ forms heteroleptic $\left.\left[\{\text { (dioxane })_{6} \mathrm{~K}_{2} \mathrm{Mn}_{2}\left(\mathrm{CH}_{2} \mathrm{SiMe}_{3}\right)_{4}\left(\mathrm{O}\left(\mathrm{CH}_{2}\right)_{2} \mathrm{OCH}=\mathrm{CH}_{2}\right)_{2}\right\}_{\infty}\right]$ (6) containing two alkoxide-vinyl anions resulting from $\alpha$-metalation and ring opening of dioxane. Compounds 6 and 7 , containing two spin carriers exhibit antiferromagnetic coupling of their $S=5 / 2$ moments with varying intensity depending on the nature of the exchange pathways.
\end{abstract}

\section{Introduction}

Polar organometallic reagents have long been essential tools in the synthetic chemists' toolbox. ${ }^{1}$ Following in the footsteps of the long-standing organolithium and Grignard reagents, a new generation of bimetallic systems, combining metals of markedly different polarities, has emerged as a family of versatile and efficient reagents that can effectively promote many cornerstone

[a] M. Uzelac, M. Amores, Dr. T. Cadenbach, Dr. A. R. Kennedy, Prof. E. Hevia

WestCHEM, Department of Pure and Applied Chemistry

University of Strathclyde

295 Cathedral Street, Glasgow, UK, G1 1XL.

E-mail eva.hevia@strath.ac.uk

[b] I. Borilovic, Prof. G. Aromí

Departament de Química Inorgànica

Universitat de Barcelona

Diagonal 645, 08028, Barcelona, Spain

E-mail:guillem.aromi@qi.ub.es

[c] Current address Dr. T. Cadenbach

Escuela Politécnica Nacional, Departamento De Física

Ladron de Guevera E11-253, Quito 170517, Ecuador

Supporting information for this article is available on the WWW under http://dx.doi.org/10.1002/chem2015xxxx. CCDC 14401251440131 contain the supplementary crystallographic data. organic transformations. ${ }^{2}$ By switching on metal $\cdots$ metal cooperativity, these reagents can exhibit greatly enhanced performances over traditional single-metal systems, allowing the use of milder reaction conditions, and enabling in some cases synergic regioselectivities which cannot be replicated by their monometallic components. Most of these studies have focused on main-group metal systems which combine an alkali-metal with a more electronegative metal such as $\mathrm{Mg}, \mathrm{Zn}$ (pseudo main group because of its $s^{2} \rightarrow s^{0}$ reactivity) or $\mathrm{Al}^{3}$ Notable key breakthroughs in the field include Knochel's turbo-Grignard reagents $\mathrm{RMgCl} \cdot \mathrm{LiCl}(\mathrm{R}=$ alkyl or 2,2,6,6-tetramethylpiperidide, TMP) which allow the functionalization of a wide range of organic molecules via either deprotonative metallation or metalhalogen exchange processes ${ }^{4}$ or Uchiyama's recent report that ( $\mathrm{Ar}) \mathrm{AlCl}_{2} \cdot \mathrm{LiCl}$ reagents can undergo cross-coupling reactions with organic halides without the usual need of a transition metal catalyst. ${ }^{5}$ Alkali-metal magnesiates and zincates have also been successfully applied for trapping and stabilizing highly sensitive anions $^{6}$ as well as for promoting unique dimetallation reactions including the recent unprecedented meta-meta' dimagnesiation of $\mathrm{N}, \mathrm{N}$-dimethylaniline. Highlighting the critical importance of aggregation and donor-solvent effects in mixed-metal chemistry, this study has revealed that this unique regioselectivity is templated by the supramolecular structure of the bimetallic base. ${ }^{7}$ Contrastingly, the chemistry of heterobimetallic systems which incorporate a transition metal as the divalent partner for the alkali-metal has been much less developed. Focusing on $\mathrm{Mn}(\mathrm{II})$, lithium tri- and tetra-alkyl manganates (usually prepared in situ via salt-metathesis or $\mathrm{Mn}$ insertion protocols) ${ }^{8}$ have proved to be efficient reagents in organic synthesis for bringing about key transformations including radical cyclizations, 1,4additions, Mn-halogen exchange and homo- and cross-coupling processes to name just a few. ${ }^{9}$ Moreover, Mulvey recently demonstrated the ability of the structurally defined sodium manganate [(TMEDA)NaMn(TMP) $\left.\left(\mathrm{CH}_{2} \mathrm{SiMe}_{3}\right)_{2}\right]$ (TMEDA = $N, N, N$, $N$ '-tetramethylethylenediamine, $\quad$ TMP $=2,2,6,6$ tetramethylpiperidide) to promote direct $\mathrm{Mn}-\mathrm{H}$ exchange reactions of aromatics, ${ }^{10}$ mimicking in some cases reactivities previously reported for related alkali-metal magnesiate systems. Furthermore, lithium and magnesium triorganomanganates have also been proposed to be transient intermediates in $\mathrm{MnCl}_{2}$-catalysed homo and heterocoupling reactions of organolithium and Grignard reagents. ${ }^{11}$ Surprisingly, despite several excellent organic studies which highlight the synthetic utility of these bimetallic compounds, the information available on the constitution and stability of these alkali-metal manganates remains scant. ${ }^{12}$ Starting to fill this gap of knowledge and building on our previous work on main-group heterobimetallic (ate) compounds, ${ }^{13}$ here we extend our studies to alkali-metal manganate chemistry. By systematically probing the co-complexation reactions of $\left[\mathrm{MCH}_{2} \mathrm{SiMe}_{3}\right](\mathrm{M}=\mathrm{Na}$ or $\mathrm{K})$ 
with $\left[\mathrm{Mn}\left(\mathrm{CH}_{2} \mathrm{SiMe}_{3}\right)_{2}\right]$ in a variety of solvent combinations, containing in some cases Lewis donors of different hapticities and coordinative properties, a new family of tris(alkyl) alkalimetal manganates is presented. The influence that the alkalimetal and these Lewis donors impose on the structures and magnetic properties of these bimetallic species has been quantified by combining X-ray crystallography with SQUID magnetization measurements and EPR spectroscopy.

\section{Results and Discussion}

Syntheses. Following previous successes in the synthesis of solvent-free alkali-metal magnesiates and zincates, we started our investigations assessing the co-complexation reactions between Wilkinson's $\mathrm{Mn}$ (II) dialkyl compound $\mathrm{Mn}\left(\mathrm{CH}_{2} \mathrm{SiMe}_{3}\right)_{2}{ }^{14}$ and the heavier alkali-metal alkyls $\mathrm{M}\left(\mathrm{CH}_{2} \mathrm{SiMe}_{3}\right)(\mathrm{M}=\mathrm{Na}, \mathrm{K})^{15}$ in the non-coordinating solvent hexane. The heteroneopentyl ligand $\mathrm{Me}_{3} \mathrm{SiCH}_{2}{ }^{-}$was selected primarily due to its lack of $\beta$ hydrogen atoms, considerable steric bulk and electronic stabilization when compared to carbon-only-based alkyl groups that are prone to decomposition processes. ${ }^{16}$ Addition of the arene solvent and gentle heating of the resulting suspensions resulted in the formation of orange solutions that on cooling deposited crystals of the homoleptic alkali-metal manganates
$\left[\left\{\mathrm{NaMn}\left(\mathrm{CH}_{2} \mathrm{SiMe}_{3}\right)_{3}\right\}_{\infty}\right](1)$ and $\left[\left\{\mathrm{KMn}\left(\mathrm{CH}_{2} \mathrm{SiMe}_{3}\right)_{3} \cdot \mathrm{C}_{6} \mathrm{H}_{6}\right\}_{2}\right]$ (2) in yields of 68 and $67 \%$ respectively (Scheme 1 ).

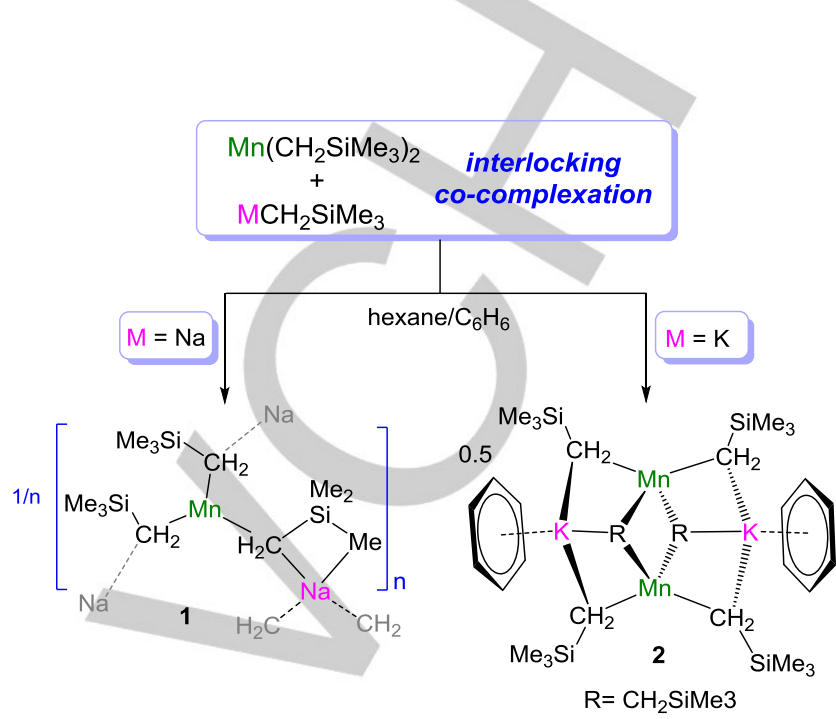

Scheme 1. Synthesis of homoleptic, trisalkyl alkali-metal manganates 1 and 2

The effect of adding Lewis donors 1,4-dioxane, TMEDA and 1,4diazabicyclo[2.2.2]octane (DABCO) to manganates 1 and 2 was investigated (Scheme 2).

0.5

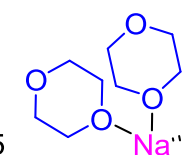

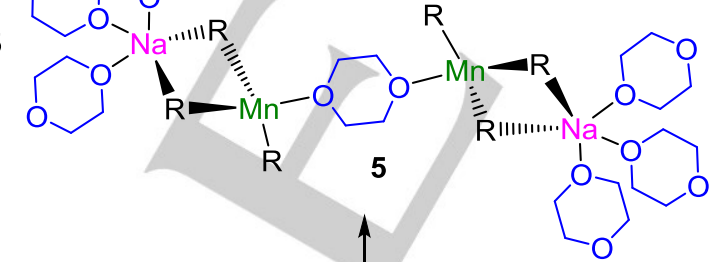
$\mathrm{M}=\mathrm{Na} \quad$ (ii) 4 eq dioxane

$1 / 2 n$

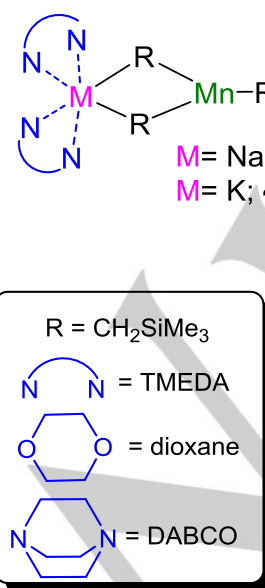

$$
\frac{\text { (i) } 2 \text { eq }}{\text { TMEDA }}
$$

$$
1 / x\left[\left(\mathrm{C}_{6} \mathrm{H}_{6}\right)_{\mathrm{y}} \mathrm{MMnR}\right]_{\mathrm{x}}
$$$$
\mathrm{M}=\mathrm{Na} ; \mathrm{x}=\mathrm{n} ; \mathrm{y}=0 ; 1
$$$$
\mathrm{M}=\mathrm{K} ; \mathrm{x}=2 ; \mathrm{y}=1 ; 2
$$$$
\mathrm{M}=\mathrm{Na}
$$$$
\downarrow
$$
(v) 1 eq $\mathrm{DABCO}$

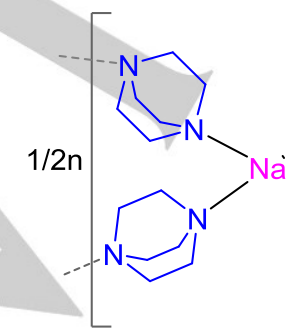

7 (ii) 4 eq dioxane $\mathrm{M}=\mathrm{K}$<smiles>CCN(C)CCCN(C)CC</smiles>

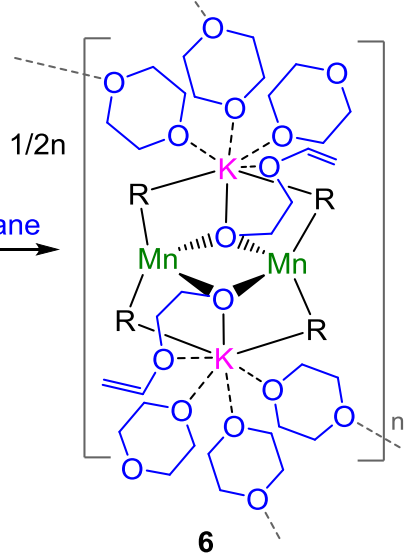


Using two molar equivalents of bidentate $\mathrm{N}$-donor TMEDA allowed the isolation of complexes [(TMEDA $)_{2} \mathrm{MMn}\left(\mathrm{CH}_{2} \mathrm{SiMe}_{3}\right)_{3}$ ] $(\mathrm{M}=\mathrm{Na}, 3 ; \mathrm{M}=\mathrm{K}, 4)$ in $65 \%$ and $69 \%$ yields respectively. Interestingly, disclosing an important alkali-metal effect, the reactions of $\mathbf{1}$ and $\mathbf{2}$ with 1,4-dioxane (four equivalents) produced an entirely different outcome (Scheme 2). Thus while the sodium manganate $\mathbf{1}$ formed coordination adduct $\left.\left[\left\{\mathrm{NaMn}\left(\mathrm{CH}_{2} \mathrm{SiMe}_{3}\right)_{3}\right\}_{2} \text { (dioxane) }\right)_{7}\right] \quad$ (5) $\quad(52 \%$ yield), potassium manganate 2 yielded heteroleptic species $\left[\left\{(\text { dioxane })_{6} \mathrm{~K}_{2} \mathrm{Mn}_{2}\left(\mathrm{CH}_{2} \mathrm{SiMe}_{3}\right)_{4}\left(\mathrm{O}\left(\mathrm{CH}_{2}\right)_{2} \mathrm{OCH}=\mathrm{CH}_{2}\right)_{2}\right\}_{\infty}\right] \quad(6) \quad(45 \%$ yield), which contains two alkyl groups, three solvating molecules of dioxane and surprisingly an alkoxy vinyl ether ligand (Scheme 2), resulting from the alpha metalation and ring opening of the remaining molecule of dioxane (vide infra). Adding bicyclic diamine donor DABCO to a solution of $\mathbf{1}$ in hexane afforded a white precipitate that could be dissolved in hot toluene, giving a brown solution that deposited colorless crystals of $\left[\left\{\mathrm{Na}_{2} \mathrm{Mn}_{2}\left(\mathrm{CH}_{2} \mathrm{SiMe}_{3}\right)_{6}(\mathrm{DABCO})_{2}\right\}_{\infty}\right]$ (7) on cooling to room temperature in a $43 \%$ yield. Attempts to isolate a product from the same reaction using potassium manganate 2 led to the isolation of a white microcrystalline material which was not amenable for X-ray analysis.

Alkali-metal manganates 1-7 were characterized by $\mathrm{X}$-ray crystallography, EPR spectroscopy and elemental analysis and they also had their magnetic susceptibilities measured on a SQUID magnetometer.

\section{Solid-State Structures.}

Unsolvated sodium manganate 1 displays an infinitely aggregated structure, comprising dinuclear $\left\{\mathrm{NaMn}\left(\mathrm{CH}_{2} \mathrm{SiMe}_{3}\right)_{3}\right\}$ units (Figure 1a) where each alkyl group acts as a bridge between $\mathrm{Mn}$ and $\mathrm{Na}$ centers via their methylene group, giving rise to an intricate two-dimensional network (Fig 1c). Its basic repeat unit features a distorted trigonal-planar $\mathrm{Mn}$ (sum of angles around $\mathrm{Mn}=359.03^{\circ}$ ) bonded to three monosilyl $\mathrm{CH}_{2} \mathrm{SiMe}_{3}$ groups, one of which bridges to sodium (Fig 1a). The two remaining alkyl ligands bond to $\mathrm{Na}$ atoms of a neighbouring unit, building a $2 \mathrm{D}$ honeycomb sheet structure which contains 12-membered $\left\{(\mathrm{NaCMnC})_{3}\right\}$ fused rings with the $\mathrm{SiMe}_{3}$ groups alternately pointing to opposite faces of the sheet. Each of these rings accommodates 6 metals $(3 \mathrm{Na}, 3 \mathrm{Mn}$ ) and 6 monosilyl ligands (Fig 1b) and is interconnected with another six rings within the polymeric structure (Fig 1c). Additionally, each $\mathrm{Na}$ gains further stabilization by forming a secondary electrostatic interaction with the methyl group of one $\mathrm{CH}_{2} \mathrm{SiMe}_{3}$ ligand $[\mathrm{Na} 1 \cdots \mathrm{C} 8,3.020(1) \AA]$, which induces a slight pyramidalisation in its geometry (sum of bond angles around $\mathrm{Na}=352.9^{\circ}$ ) Inspection of the sodium-carbon distances within 1 (Table 1) shows that there is no significant variation that would define a specific molecular unit. Thus all three $\mathrm{Na}-\mathrm{C}$ distances in $1 \mathrm{lie}$ within relatively small range $[2.653(4)$ to $2.705(4) \AA]$. Similarly, no significant difference is found between the three $\mathrm{Mn}-\mathrm{C}$ bond lengths of 1 [range: 2.166(4)-2.180(4) Å]. These values are slightly elongated compared to those reported for the discrete monomeric NHC-complex [( $\left.\mathrm{IPr}) \mathrm{Mn}\left(\mathrm{CH}_{2} \mathrm{SiMe}_{3}\right)_{2}\right](\mathrm{IPr}=1,3$ bis(2,6-diisopropylphenyl)imidazol-2-ylidene), which also contains a tricoordinated $\mathrm{Mn}$ center $\left(\mathrm{Mn}-\mathrm{C}_{\text {alkyl }}\right.$ bond length, 2.129(1) $\AA] .{ }^{17}$ Reflecting the structural similarities previously noticed between organomagnesium and organomaganese (II) compounds, ${ }^{12 c, 17,18}$ the intriguing $2 \mathrm{D}$ honeycomb assembly of $\mathbf{1}$, although unique in manganate chemistry, is isostructural to that previously reported by our group for magnesiate $\left[\left\{\mathrm{NaMg}\left(\mathrm{CH}_{2} \mathrm{SiMe}_{3}\right)_{3}\right\}_{\infty}\right] .{ }^{13}$ This ring-fused structure contrasts with those found for the monometallic components of $\mathbf{1}$, which are also highly aggregated but display polymeric chain arrangements made up in each case by association of $\left\{\mathrm{Mn}_{2}\left(\mathrm{CH}_{2} \mathrm{SiMe}_{3}\right)_{2}\right\}$ dimers ${ }^{19}$ or $\left\{\mathrm{Na}\left(\mathrm{CH}_{2} \mathrm{SiMe}_{3}\right)\right\}_{4}$ tetramers. ${ }^{13}$

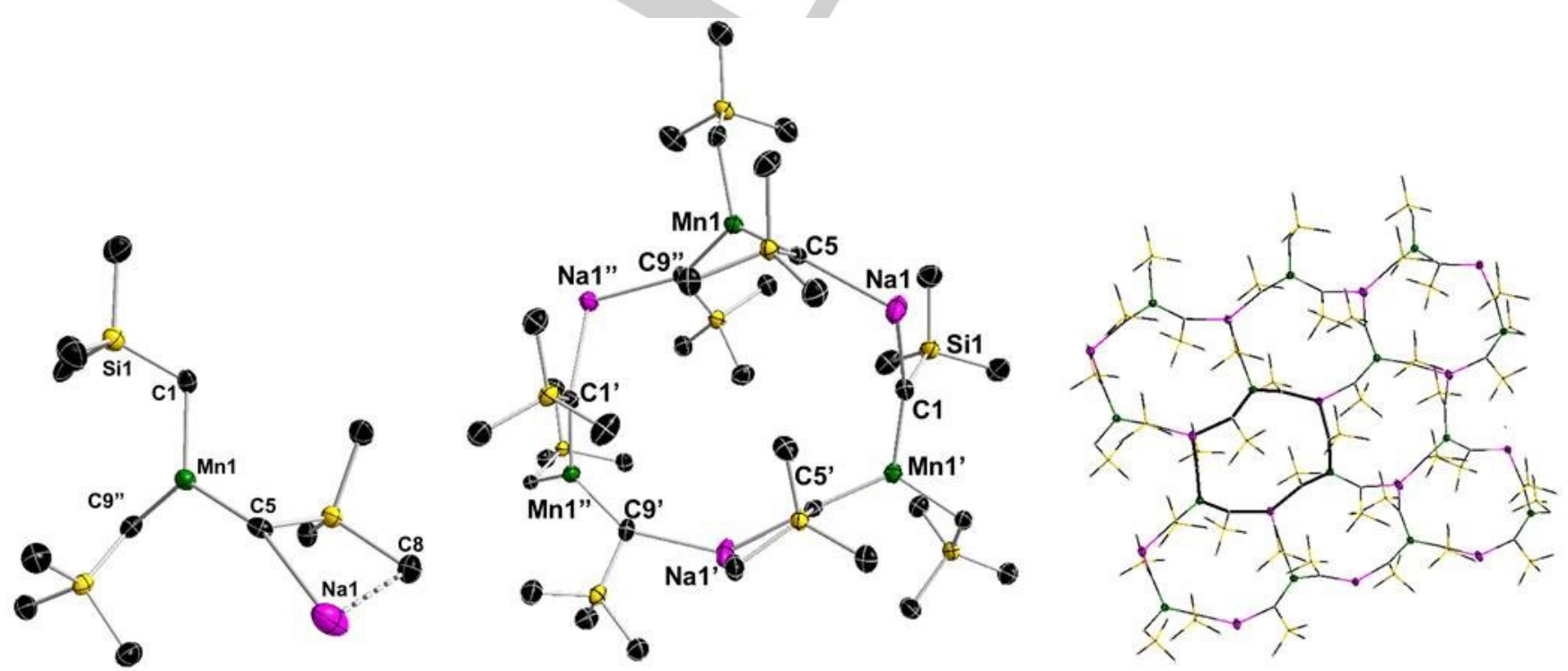

Figure 1. (a) Asymmetric unit of 1; (b) section of polymeric 1 showing a 12-membered $\{\mathrm{NaCMnC}\}_{3}$ ring; and (c) wire representation of polymeric sheet network of 1. In all figures hydrogen atoms have been omitted for clarity and ellipsoids are drawn in $50 \%$ probability. Symmetry operators ('): $x+0.5$, $y,-z+0.5$; ('): $-x+0.5$ $y+0.5, z ;(" ')-x+0.5, y-0.5, z$; ('”') $x-0.5, y,-z+0.5$. 


\begin{tabular}{|c|c|c|c|c|c|}
\hline & $\mathrm{M}=\mathrm{Na}(\mathbf{1})$ & $\mathrm{M}=\mathrm{Na}(3)$ & $M=K(4)$ & $M=N a, X=O(5)$ & $M=N a, X=N(7)$ \\
\hline Mn1-C1 & $2.166(4)$ & $2.176(2)$ & $2.174(3)$ & $2.170(2)$ & $2.254(3)$ \\
\hline Mn1-C5 & $2.180(4)$ & $2.171(2)$ & $2.176(3)$ & $2.230(2)$ & $2.214(3) ; 2.419(3)^{[c]}$ \\
\hline Mn1-C9 & $2.177(4)^{[a]}$ & $2.155(2)$ & $2.156(3)$ & $2.208(2)$ & $2.202(3)$ \\
\hline $\mathrm{Mn} 1-\mathrm{X} 1$ & - & - & - & $2.3271(12)$ & - \\
\hline Average $\mathrm{Mn} 1-\mathrm{C}$ & 2.174 & 2.167 & 2.169 & 2.203 & 2.272 \\
\hline M-C1 & $2.705(4)^{[\mathrm{b}]}$ & $3.079(2)$ & $3.163(3)$ & & $2.558(1)$ \\
\hline M-C5 & $2.653(4)$ & $3.025(2)$ & $3.199(3)$ & $2.694(2)$ & - \\
\hline M-C9 & $2.664(4)$ & - & - & $2.719(2)$ & $2.721(1)$ \\
\hline Average $\mathrm{M}-\mathrm{C}$ & 2.674 & 3.052 & 3.181 & 2.706 & 2.639 \\
\hline M-Mn1 & - & $3.5513(9)$ & $3.6468(8)$ & $3.3150(8)$ & $3.0919(10)$ \\
\hline
\end{tabular}

[a] This distance represents Mn1-C9" (symmetry operator: $-x+0.5, y+0.5, z)$. [b] This distance represents Mn1-C5' (symmetry operator: $x,-y-0.5$, $z-0.5)$. [c] This distance represents Mn1-C5' (symmetry operator: $-x,-y,-z)$.

In general, donor free alkali-metal ate structures are rare in heterobimetallic chemistry due to solubility issues or difficulty in generating $\mathrm{X}$-ray quality crystals. In manganate chemistry, Ernst has reported the structure of the substituted tris(dienyl) $[\mathrm{K}\{\mathrm{Mn}(3-$ $\left.\left.\left.\mathrm{Me}-1,5-\left(\mathrm{Me}_{3} \mathrm{Si}\right) \mathrm{C}_{5} \mathrm{H}_{4}\right)_{3}\right\}\right]$ which forms a discrete monomer, where $\mathrm{K}$ is trapped within the three dienyl ligands, through $\pi$-engaging with the $\mathrm{C}=\mathrm{C}$ bonds. ${ }^{20}$

As far as we can ascertain, 1 constitutes the first example of an unsolvated alkali-metal manganate with an extended structure as well as the first homo(alkyl) sodium manganate to be structurally defined. Switching to the heavier alkali-metal potassium facilitated the synthesis and isolation of benzenesolvated manganate $\mathbf{2}$, which, contrasting with polymeric $\mathbf{1}$, features a discrete dimeric arrangement and has incorporated two molecules of benzene in its constitution, each of them $\pi$ engaging with a $\mathrm{K}$ center. Centrosymmetric 2 can be described as a cationic octagonal $\left[(\mathrm{KCMnC})_{2}\right]^{2+}$ ring hosting two monosilyl anion guests that are $\mu_{3}$-capped at the top and bottom of the ring by binding to two $\mathrm{Mn}$ and one $\mathrm{K}$ ( $\mathrm{C} 11$ and $\mathrm{C} 11^{\prime}$ in Fig 2b). Within 2, tetracoordinated $\mathrm{Mn}$ exhibits a distorted tetrahedral geometry, bonded to four alkyl groups [range of $\mathrm{CMnC}$ bond angles, $103.04(12)^{\circ}-119.97(12)^{\circ}$; mean $109.16^{\circ}$ ]. Unsurprisingly, the $\mathrm{Mn}-\mathrm{C}$ distances for the $\mu_{2}$-alkyls that are part of the eightmembered ring and coordinate to $\mathrm{K}$ and $\mathrm{Mn}$ are shorter [2.186(3) and 2.198(3) $\AA$ ] than those for the $\mu_{3}$-guest alkyls $[\mathrm{Mn} 1-\mathrm{C} 11,2.235(3) \AA]$, this difference being particularly noticeable for Mn1-C11' 2 2.488(3) $\AA$, Table 2]. ${ }^{21}$ This trend is even more evident for the K-C distances, with the $\mu_{2}$-alkyls (C7 and C15, Fig 2a) forming significantly shorter bonds [mean value, $3.030(4) \AA]$ than the remaining $\mu_{3}$-ligands $[\mathrm{K} 1-\mathrm{C} 1,3.374(4) \AA] .^{22}$

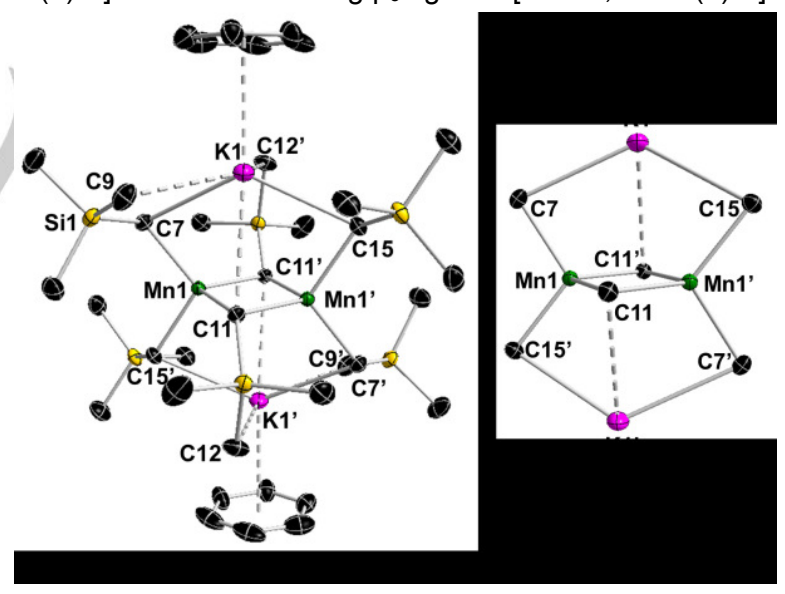

Figure 2. (a) Molecular structure of 2. (b) Framework of 2 with benzene molecules and $\mathrm{SiMe}_{3}$ substituents omitted for clarity. In all figures hydrogen atoms have been omitted for clarity and ellipsoids are drawn in $50 \%$ probability. Dotted lines represent secondary K-C interactions. Symmetry operator: $-\mathrm{x},-\mathrm{y}$, $z+1$.

In addition, two further long-distance stabilizing secondary interactions are observed for each $\mathrm{K}$ with the Me groups of two different $\mathrm{SiMe}_{3}$ units [K1-C12, 3.3738(6) A and K1-C9, 3.2462(4) $\AA$ ]. Potassium completes its coordination by engaging with the $\mathrm{C}=\mathrm{C} \pi$-bonds of a molecule of benzene which coordinates in an essentially $\eta^{6}$-fashion $[\mathrm{K}-\mathrm{C}$ distances lie the narrow range 3.285(13)-3.407(12) $\AA]{ }^{23}$ The internuclear $\mathrm{Mn} \cdots \mathrm{Mn}$ separation in $2[2.8716(10) \AA]$ is comparable with those found for 
homometallic [ $\left.\left\{\mathrm{Mn}\left(\mathrm{CH}_{2} \mathrm{SiMe}_{3}\right)_{2}\right\}_{\infty}\right]$ [mean, $2.8885 \AA$ ] and $\left[\left\{\text { Mn }(\text { Mesityl })_{2}\right\}_{3}\right]$ [mean $\left.2.8515 \AA\right]^{24}$ and is considerably more elongated than that recently reported by Hayton in the ketimidebridged dimer $\left[\mathrm{Li}([12] \text { crown-4 })_{2}\right]\left[\mathrm{Mn}_{2}\left(\mathrm{~N}=\mathrm{C}^{t} \mathrm{Bu}_{2}\right)_{5}\right] \quad[\mathrm{Mn} \cdots \mathrm{Mn}$ 2.5965(7) $\AA$ ], which exhibits strong metal-metal electronic communication between the two Mn centers as determined by solid state magnetic susceptibility measurements using SQUID magnetometry. ${ }^{25}$

\begin{tabular}{|ll|ll|}
\hline \multicolumn{3}{|c|}{ Table 1. Selected bond distances $(\AA)$ for potassium manganate 2. } \\
\hline Mn1-C7 & $2.186(3)$ & K1-C7 & $3.011(4)$ \\
\hline Mn1-C15' & $2.198(3)$ & K1-C15 & $3.050(4)$ \\
\hline Mn1-C11' & $2.235(3)$ & K1-C12' & $3.374(4)$ \\
\hline Mn1-C11 & $2.488(3)$ & K1-C11 & $3.375(3)$ \\
\hline Mn1'-C11 & $2.235(3)$ & Average K-C & 3.202 \\
\hline Mn1'-C15 & $2.198(3)$ & Mn1-K1 & $3.4712(10)$ \\
\hline Average Mn1-C & 2.277 & Mn1-K1' & $3.5202(10)$ \\
\hline Mn1 ‥Mn1' & $2.8716(10)$ & & \\
\hline
\end{tabular}

The basic motif of $\mathbf{2}$, sometimes alternatively described as a face-fused double heterocubane structure with two missing corners or as some type of inverse crown complex has been previously found in a variety of s-block homo- and heterobimetallic compounds, ${ }^{26}$ however we believe it is unique for a homo(alkyl) ate system. ${ }^{27}$ Unlike sodium manganate 1 , the structure of $\mathbf{2}$ is strikingly different to that of its magnesiate analog $\left[\left\{\mathrm{KMg}\left(\mathrm{CH}_{2} \mathrm{SiMe}_{3}\right)_{3} \cdot \mathrm{C}_{6} \mathrm{H}_{6}\right\}_{\infty}\right]$ which forms an infinitely aggregated $2 \mathrm{D}$ network. ${ }^{28}$

Addition of two equivalents of bidentate nitrogen donor TMEDA to manganates 1 and 2 caused their deaggregation forming discrete monomeric triorganomanganates $\left[(\mathrm{TMEDA})_{2} \mathrm{MMn}\left(\mathrm{CH}_{2} \mathrm{SiMe}_{3}\right)_{3}\right] \quad 3(\mathrm{M}=\mathrm{Na})$ and $4(\mathrm{M}=\mathrm{K})$ respectively with the same ring-closed contacted ion pair motif (Fig 3 and Fig S2).

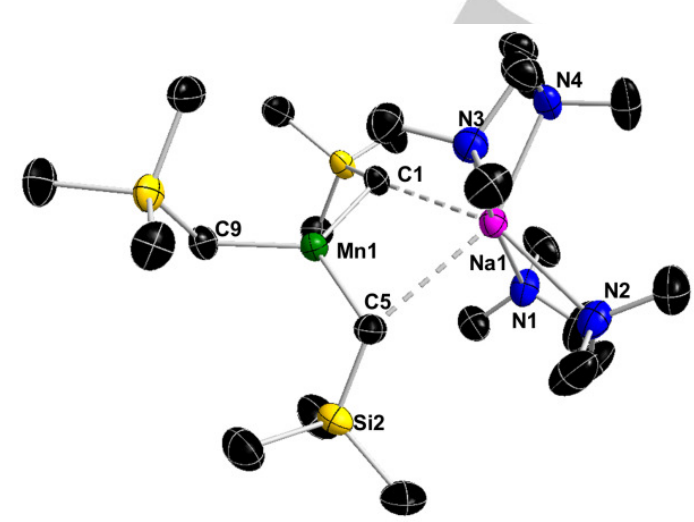

Figure 3. Molecular structure of $\mathbf{3}$ with $50 \%$ probability displacement ellipsoids All hydrogen atoms have been omitted for clarity. Dotted lines represent longer Na-C interactions.
Both compounds display a $\mathrm{C}_{3}$-tricoordinated $\mathrm{Mn}$ atom (sum of the angles around $\mathrm{Mn}, 360.00$ for both 3 and 4 ), where two alkyl groups bridge to the doubly chelated cation $\left\{(\text { TMEDA })_{2} M\right\}^{+}(M=$ $\mathrm{Na}$ or K). As shown in Table 1, the Mn-C bond distances in 3 and 4 are very similar [ranging from $2.155(2)$ to $2.176(3) \AA$ ] and show almost no variation to those found in unsolvated sodium manganate 1 which also contains a tricoordinated Mn center [mean value, $2.173 \AA$, see Table 1 for details]. Contrastingly, a comparison between the $\mathrm{Na}-\mathrm{C}$ distances in 1 and 3 revealed a significant elongation for the latter [mean values, 2.676 vs 3.052 $\AA$ ]. A different trend is observed for the K-C distances in 2 and 4 which are relatively well matched [mean values, 3.202 vs 3.181 $\AA$ ] and can be attributed to the fact that in both structures the $K$ cations are hexacoordinated. The formation of potassium triorganomanganate $\mathbf{4}$ contrast sharply with the reactivity recently reported for magnesiate $\left[\left\{\mathrm{KMg}\left(\mathrm{CH}_{2} \mathrm{SiMe}_{3}\right)_{3} \cdot \mathrm{C}_{6} \mathrm{H}_{6}\right\}_{\infty}\right]$ where the bidentate ligand TMEDA not only induces the deaggregation of its polymeric structure but also causes a redistribution process forming higher-order tetraorganomagnesiate [(TMEDA $\left.)_{2} \mathrm{NaMg}\left(\mathrm{CH}_{2} \mathrm{SiMe}_{3}\right)_{4}\right]$ along with the elimination of $\left[\mathrm{Mg}\left(\mathrm{CH}_{2} \mathrm{SiMe}_{3}\right)_{2}\right] .{ }^{28}$

Addition of O-donor dioxane to manganates $\mathbf{1}$ and $\mathbf{2}$ led to the isolation of $\left[\left\{\mathrm{NaMn}\left(\mathrm{CH}_{2} \mathrm{SiMe}_{3}\right)_{3}\right\}_{2}(\text { dioxane })_{7}\right] \quad$ (5) and [\{(dioxane $\left.\left.)_{6} \mathrm{~K}_{2} \mathrm{Mn}_{2}\left(\mathrm{CH}_{2} \mathrm{SiMe}_{3}\right)_{4}\left(\mathrm{O}\left(\mathrm{CH}_{2}\right)_{2} \mathrm{OCH}=\mathrm{CH}_{2}\right)_{2}\right\}_{\infty}\right]$ respectively which exhibit completely different constitutions and structural motifs. Possessing two oxygen atoms at positions 1 and 4 , which generally precludes this bidentate donor from acting as a chelating ligand, dioxane is well-known to facilitate aggregation by linking metal atoms together through $M$ $\mathrm{O}\left(\mathrm{CH}_{2}\right)_{4} \mathrm{O}-\mathrm{M}$ bridges. ${ }^{29,30}$ Displaying a discrete dimeric arrangement (Figure 4), 5 contains two $\left\{(\text { dioxane })_{3} \mathrm{NaMn}\left(\mathrm{CH}_{2} \mathrm{SiMe}_{3}\right)_{3}\right\}$ units which are connected by an additional bridging dioxane that solvates the Mn centers. In each of these units, the $\mathrm{Na}$ and $\mathrm{Mn}$ atoms are connected by two alkyl groups, closing four-membered $\{\mathrm{NaCMnC}\}$ rings, with a remaining alkyl bonded terminally to $\mathrm{Mn}$. Interestingly, despite the higher coordination number of $\mathrm{Mn}$ in $\mathbf{5}$ (coordinated to three $\mathrm{C}$ atoms and to one $\mathrm{O}$ atom), its mean $\mathrm{Mn}-\mathrm{C}$ bond distance is just slightly elongated [2.203 $\AA$ ] to those found in supramolecular 1 [2.173 $\AA$ ] and discrete monomer 3 [2.167 $\AA$ ] (See Table 1 for details).

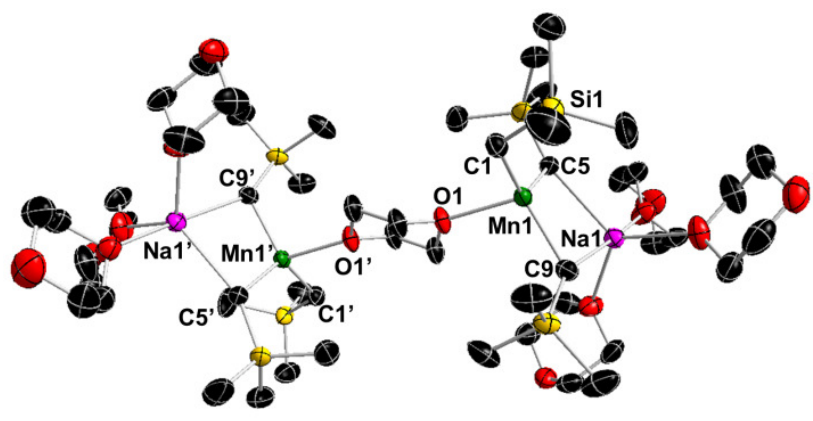

Figure 4. Dimeric structure of $\mathbf{5}$ with $50 \%$ probability displacement ellipsoids. All hydrogen atoms and minor disorder in two terminal 1,4-dioxane molecules have been omitted for clarity. Symmetry operator: $-x,-y,-z+2$. 
Showing a more markedly effect, penta-coordinated distorted trigonal bipyramidal $\mathrm{Na}$ centers form significantly stronger (shorter) bonds with the alkyl groups [2.706 $\AA$ ] than those found for 3 [3.052 $\AA$ ] where $\mathrm{Na}$ is in a distorted octahedral environment (vide supra).

X-ray crystallographic studies of 6 uncovered its heteroleptic anionic constitution, containing a 2:1 ratio of monosilyl groups and alkoxy vinyl ether residues, with the latter resulting from fragmentation of 1,4 dioxane. Exhibiting a similar core structure to that of precursor 2 , the asymmetric unit in $\mathbf{6}$ is made up by a cationic octagonal $\left[(\mathrm{KCMnC})_{2}\right]^{2+}$ ring which is now hosting two alkoxy vinyl ether anion $\left\{\mathrm{OCH}_{2} \mathrm{CH}_{2} \mathrm{OCH}=\mathrm{CH}_{2}\right\}$ guests (Figure $5 b)$.

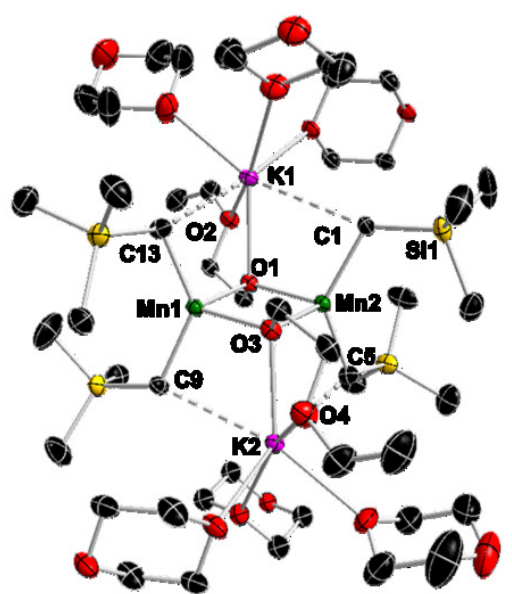

(a)

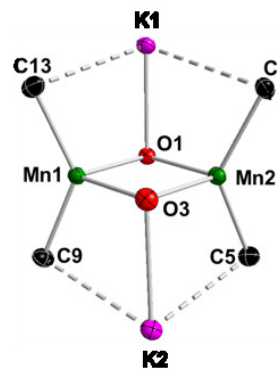

(b)
Figure 5. (a) Asymmetric unit of 6. (b) Framework of 6 with dioxane molecules, $\mathrm{SiMe}_{3}$ substituents and alkoxy vinyl substituents omitted for clarity. In all figures hydrogen atoms and minor disorder in two coordinated 1,4-dioxane molecules have been omitted for clarity and ellipsoids are drawn in 50\% probability. Dotted lines represent secondary K-C interactions.

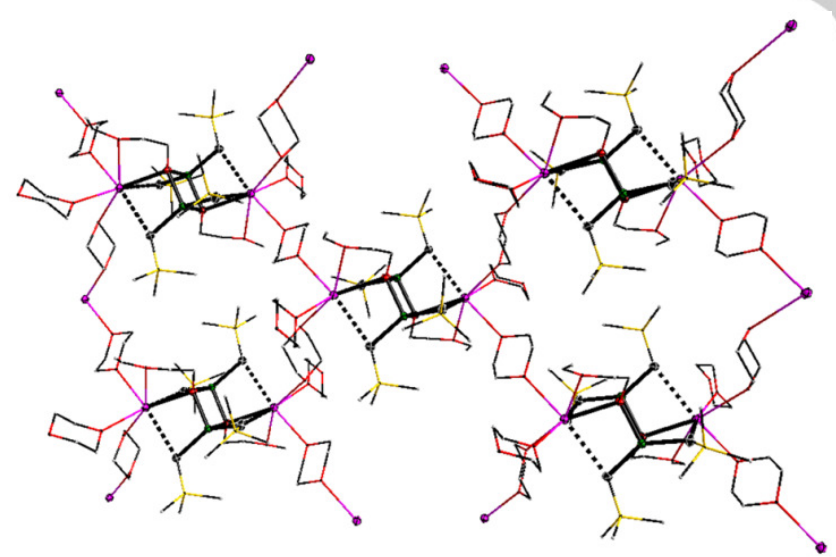

Figure 6. Wire model representation of polymeric structure of 6 with core atoms drawn in $50 \%$ probability displacement ellipsoids. All hydrogen atoms and minor disorder in coordinating 1,4-dioxane molecules have been omitted for clarity. Symmetry operators \#1: $-x+1,-y+1,-z+2 ; \# 2:-x,-y+1,-z+2 ; \# 3$ : $-x,-$ $y+2,-z+3 ; \# 4:-x+1,-y+2,-z+3$. Dotted lines represent secondary $K-C$ interactions.
Each alkoxy anion interconnects two $\mathrm{Mn}$ atoms with one $\mathrm{K}$ (via $\mathrm{O} 1$ and $\mathrm{O} 3$, Figure 5) and uses its ether oxygen (O2 and $\mathrm{O} 4$ respectively) to chelate a $\mathrm{K}$ center. Attaining heptacoordination, each $\mathrm{K}$ atom is further solvated by three molecules of dioxane, two of which are bridging to other $\mathrm{K}$ centers from neighboring $\left\{\mathrm{K}_{2} \mathrm{Mn}_{2}\left(\mathrm{CH}_{2} \mathrm{SiMe}_{3}\right)_{4}(\mathrm{OR})_{2}\right\} \quad\left(\mathrm{R}=\quad \mathrm{CH}_{2} \mathrm{CH}_{2} \mathrm{OCH}=\mathrm{CH}_{2}\right) \quad$ units assembling a $2 \mathrm{D}$ network (Figure 6).

A comparison of the main geometrical parameters of 2 and 6 revealed that while replacing the alkyl guests by alkoxide groups in the eight-membered $\left[(\mathrm{KCMnC})_{2}\right]^{2+}$ ring has little effect on the Mn-C distances [mean value $2.175 \AA$ in 6 vs 2.186(3) and 2.198(3) $\AA$ in 2], it imposes a significant elongation on the intermetallic $\mathrm{Mn} \cdots \mathrm{Mn}$ separation which is now $3.1447(4) \AA$ [2.8716(10)A for 2] as well as on the $\mathrm{K}-\mathrm{C}($ alkyl) bonds [mean value $3.219 \AA$ in 6 vs 3.011(4) and 3.050(4) $\AA$ in 2] see Table 3.

\begin{tabular}{|l|l|l|l|}
\hline \multicolumn{3}{|c|}{ Table 3. Selected bond distances $(\AA)$ for potassium manganate 6. } \\
\hline $\mathrm{Mn} 1-\mathrm{C} 9$ & $2.172(2)$ & $\mathrm{K} 1-\mathrm{C} 1$ & $3.279(1)$ \\
\hline $\mathrm{Mn} 1-\mathrm{C} 13$ & $2.175(2)$ & $\mathrm{K} 1-\mathrm{C} 13$ & $3.182(1)$ \\
\hline $\mathrm{Mn} 2-\mathrm{C} 1$ & $2.180(2)$ & $\mathrm{K} 2-\mathrm{C} 5$ & $3.156(1)$ \\
\hline $\mathrm{Mn} 2-\mathrm{C} 5$ & $2.175(2)$ & $\mathrm{K} 2-\mathrm{C} 9$ & $3.261(1)$ \\
\hline $\mathrm{Mn} 1 \cdots \mathrm{Mn} 2$ & $3.1447(4)$ & $\mathrm{K} 1 \cdots \mathrm{Mn} 1$ & $3.6171(5)$ \\
\hline
\end{tabular}

Despite ether cleavage being a problematic side reaction in organometallic chemistry, ${ }^{31}$ and 1-4 dioxane a common solvent in synthesis, the number of structurally defined intermediates resulting from this process is surprisingly scarce. In one example, Henderson has trapped the alkoxy-vinyl fragment present in $\mathbf{6}$ as a result of the cleavage of dioxane by ${ }^{\mathrm{t}} \mathrm{BuLi}{ }^{32}$ as well as by the action of a $\mathrm{Bu}_{2} \mathrm{Mg} /$ diisopropylaniline mixture. ${ }^{33}$ Closer to 6 is the fragmentation of this cyclic ether mediated by lithium aluminate $\left[\left\{\mathrm{PhC}(=\mathrm{O}) \mathrm{N}^{\mathrm{P}} \mathrm{Pr}_{2}\right\} \mathrm{LiAl}^{\mathrm{B}} \mathrm{Bu}_{3}\right]$, where the heteroleptic system metallates dioxane at its alpha position, to form a transient intermediate that can rapidly undergo ring-opening and rearrange to a vinyl modification. ${ }^{34} \mathrm{~A}$ similar process could be in operation in forming 6 (Scheme 3), suggesting an enhanced metallating power for potassium manganate 2 over its $\mathrm{Na}$ analogue 1 (where addition of dioxane only induces deaggregation of the manganate structure to form dimer $\mathbf{5}$, vide supra). a-manganation of one molecule of dioxane can be facilitated by its coordination to the $\mathrm{Mn}$ center (as seen in 5) which would bring it into close proximity to the ate activated monosilyl groups. Transformation of this proposed intermediate into final product 6 involves ring-opening of the coordinated deprotonated dioxane molecule followed by a rearrangement step to its vinyl form (Scheme 3 ). Also pertinent is the ability of alkali-metal manganates to promote the metallation and cleavage of cyclic ethers previously demonstrated by Mulvey using [(TMEDA) NaMn(TMP) $\left.\left(\mathrm{CH}_{2} \mathrm{SiMe}_{3}\right)_{2}\right]$, which induces the "catastrophic" cleavage of THF, breaking its two $\mathrm{C}-\mathrm{O}$ bonds and four $\mathrm{C}-\mathrm{H}$ bonds to form oxo and butadiene anions that are trapped by the residue of the bimetallic system. ${ }^{35}$ 


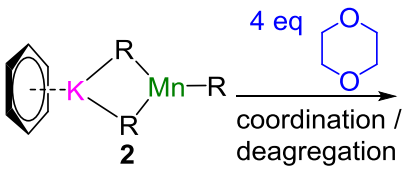<smiles>[R][R14]([R])([R])[Ge](OC1CCOCC1)(OC1CCOCC1)OC1CCOCC1</smiles>

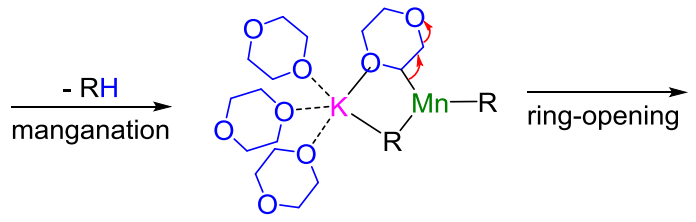<smiles>[R][M]CC([R])(OCCO)[Ge](OCCO)(OCCO)OC1COCCO1</smiles>

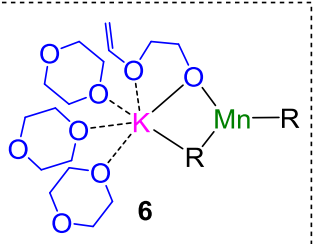

Scheme 3. Proposed stepwise mechanism for formation of 6

Finally, utilizing DABCO as a Lewis donor, which akin to 1,4 dioxane has its donor atoms arranged at geometrically opposing sites led to the isolation of sodium manganate $\left[\left\{\mathrm{Na}_{2} \mathrm{Mn}_{2}\left(\mathrm{CH}_{2} \mathrm{SiMe}_{3}\right)_{6}(\mathrm{DABCO})_{2}\right\}_{\infty}\right] \quad$ (7) where a new supramolecular assembly was revealed (Figures 7 and 8 ).

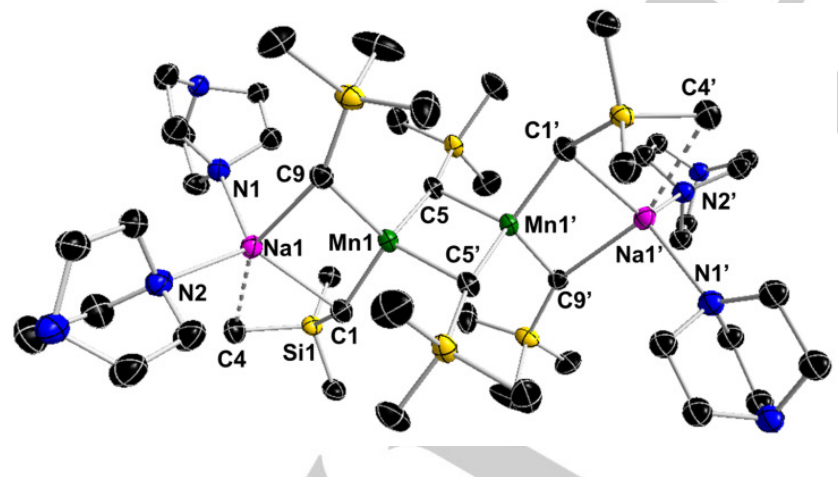

Figure 7. Molecular structure of dimeric 7 with $50 \%$ probability displacement ellipsoids. All hydrogen atoms have been omitted for clarity. Dotted lines represent secondary $\mathrm{Na}-\mathrm{C}$ interactions. Symmetry operator: $-\mathrm{x},-\mathrm{y},-\mathrm{z}$.

The basic organometallic core in centrosymmetric 7 comprises a tetranuclear $\mathrm{Na} \cdots \mathrm{Mn} \cdots \mathrm{Mn} \cdots \mathrm{Na}$ chain arrangement connected by six bridging alkyl groups. This gives rise to three planar four-membered rings, made up of two outer $\{\mathrm{NaCMnC}\}$ heterobimetallic rings which are linked through a central $\{\mathrm{MnCMnC}\}$ ring that is orthogonal to the outer rings. ${ }^{36}$ While this core motif is unprecedented in manganate chemistry, it has been previously reported in magnesiate chemistry, ${ }^{37}$ and is reminiscent to the $\mathrm{Li} \cdots \mathrm{Mn} \cdots \mathrm{Li}$ trinuclear arrangement reported by Girolami in a series of [(TMEDA $\left.)_{2} \mathrm{Li}_{2} \mathrm{MnR}_{4}\right](\mathrm{R}=\mathrm{Me}$, Et, $\mathrm{CH}_{2} \mathrm{CH}_{2} \mathrm{CMe}_{3}$ ) complexes which contains two orthogonal heterometallic $\{\mathrm{LiCMnC}\}$ four membered rings fused by their $\mathrm{Mn}$ vertex. ${ }^{12 a}$, $12 \mathrm{c}$ Each $\mathrm{Mn}$ atom in 7 is bonded to four alkyl groups with $\mathrm{Mn}-\mathrm{C}$ distances [mean value, $2.272 \AA$ ] similar to those found in 2 [mean value, $2.272 \AA \AA$ ], which also contains a $\mathrm{Mn}$ in four-carbon coordination sphere, although in this case the maganate exhibits a ring-structure instead of a linear arrangement. Two nitrogens and two carbons from DABCO and alkyl ligands respectively bond to the $\mathrm{Na}$ center, which is further stabilized by a medium-long electrostatic interaction involving a methyl from one $\mathrm{SiMe}_{3}$ group [Na $\left.\cdots \mathrm{C} 4,2.9947(1) \AA\right]$. This secondary contact translates into a significantly shorter $\mathrm{Na}-\mathrm{CH}_{2}$ bond for this alkyl group [Na1-C1, 2.5584(1) A]], which formally coordinates in an ambidentate fashion closing a fourmembered $\{\mathrm{NaCSiC}\}$ ring, than that observed for the alkyl that binds to $\mathrm{Na}$ via only its methylene group [Na-C9, 2.7206(1) $\AA$ ]. Each $\mathrm{DABCO}$ ligand on the $\mathrm{Na}$ atoms coordinates to another $\mathrm{Na}$ from a neighboring tetranuclear $\left\{\mathrm{Na}_{2} \mathrm{Mn}_{2} \mathrm{R}_{4}\right\}\left(\mathrm{R}=\mathrm{CH}_{2} \mathrm{SiMe}_{3}\right)$ fragment, giving rise to the formation of an eye-catching $2 \mathrm{D}$ network. This supramolecular assembly can be envisaged as a network of $\{\mathrm{Na}-\mathrm{DABCO}-\mathrm{Na}-\mathrm{DABCO}\}_{\mathrm{n}}$ chains in a zig-zag disposition, connected by $\left\{\mathrm{Mn}_{2} \mathrm{R}_{4}\right\}^{2-}$ linkers which bind to each $\mathrm{Na}$ in a chelating fashion by a combination of $\mathrm{Na}-\mathrm{CH}_{2}$ and $\mathrm{Na} \cdots \mathrm{Me}-\mathrm{SiMe}_{2}$ interactions (Figure 8). The closely-contacted ion-pair structure of 7 contrasts with that reported for disodium tetrabutylmagnesiate $\left.\left[\left\{\left[\mathrm{Na}_{2}(\mathrm{DABCO})_{3} \text { (toluene }\right)\right]^{2+}\left(\mathrm{Mg}^{n} \mathrm{Bu}_{4}\right)^{2-}\right\}_{\infty}\right]$, which also displays a supramolecular assembly but one that is exclusively made up of a 3D network of DABCO and toluenesolvated sodium cations storing in its interstices discrete $\left\{\mathrm{Mg}^{n} \mathrm{Bu}_{4}\right\}^{2-}$ dianions. ${ }^{38}$

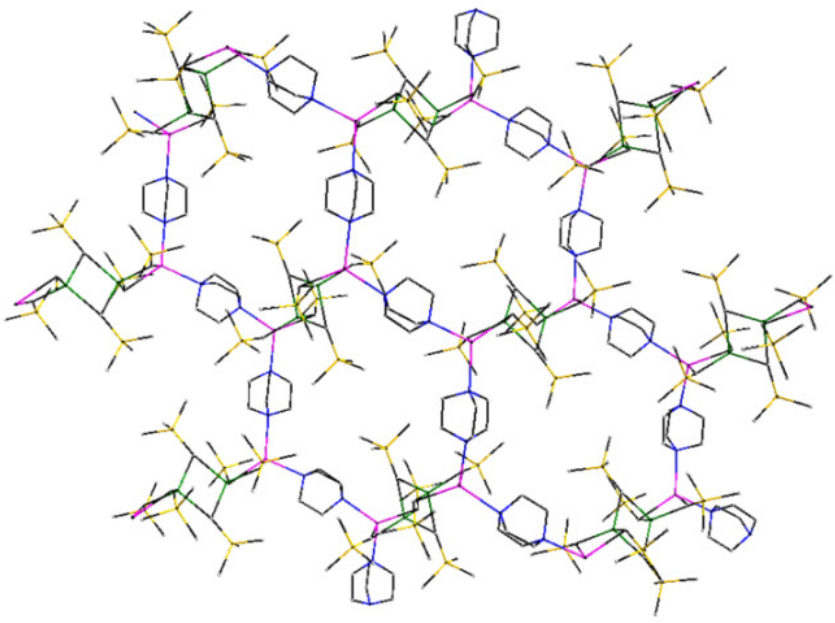

Figure 8. Wire model representation of polymeric sheet network of 7 . Hydrogen atoms have been omitted for clarity. Symmetry operators \#1: $-x,-y$, -z; \#2: -x+0.5, y+0.5, z; \#3: -x+0.5; y-0.5, z. 


\section{EPR and Magnetic Susceptibility}

In order to shed some light on the electronic structure of the $\mathrm{Mn}$ (II) centers in the various coordination environments unveiled in this family of compounds, variable temperature magnetization and EPR spectroscopy measurements were conducted. Thus, molar paramagnetic susceptibility $\left(X_{M}\right)$ data were collected from microcrystalline samples in the 2 to $300 \mathrm{~K}$ temperature range together with isothermal magnetization measurements at $2 \mathrm{~K}$ in the field range of $0-5 \mathrm{~T}$. The resulting $X_{\mathrm{M}} T$ vs $T$ curves are presented in Figures 9 and 10 (detailed experimental conditions and individual datasets with $\chi_{\mathrm{M}} T$ vs $T$, $M / N \mu_{B}$ vs $H$ curves and variable temperature EPR spectra for each compound are given in the Supporting Information).

Compounds containing one isolated magnetic metal centre (1, 3 and 4) display almost identical behaviour, fully consistent with the presence of one high-spin $(S=5 / 2) \mathrm{Mn}(\mathrm{II})$ ion. In all cases, the $X_{\mathrm{M}} T$ product at $300 \mathrm{~K}\left(3.96,4.02\right.$ and $4.19 \mathrm{~cm}^{3} \mathrm{~K} \mathrm{~mol}^{-1}$ for 1 , 3 and 4 , respectively) is slightly lower than the theoretical prediction $\left(4.375 \mathrm{~cm}^{3} \mathrm{~K} \mathrm{~mol}^{-1}, g=2.0\right.$ and $\left.S=5 / 2\right)$. However, below $250 \mathrm{~K}$ the values of $X_{\mathrm{M}} T$ are closer to these expected. The small deviation from a Curie-behaviour observed when reaching the higher temperature range is caused by slight decomposition of the samples or their oxidation to $\mathrm{Mn}$ (III) analogues occurring at these stages. To confirm this suspicion, the magnetization of compound $\mathbf{1}$ at room temperature was determined two days after the original measurement. As a result, an even lower value of the $X_{\mathrm{M}} T$ product was observed, reaching $3.43 \mathrm{~cm}^{3} \mathrm{~K} \mathrm{~mol}^{-1}$ (Figure S4). ${ }^{39}$ Below $250 \mathrm{~K}$, the original $X_{\mathrm{M}} T$ vs $T$ curves feature a small positive slope, before experiencing a sharp decrease below $7 \mathrm{~K}$. The latter is due to zero-field splitting, which inhibits also the saturation of the reduced magnetization, even in high fields (Figures S4, S10 and S13). The positive slope, which lies beyond the reasonable contribution of temperature independent paramagnetism, is often observed in organometallic $\mathrm{Mn}$ (II) compounds and has been attributed to the contribution of low-spin states to the susceptibility. ${ }^{12 e}, 40$ An additional explanation could be the contribution of a very small amount of antiferromagnetically coupled impurities. ${ }^{41}$ Variable temperature X-band EPR spectra of a powdered sample of compound 1 show two very broad transitions centred at $g=5.49$ and $g=2.03$. The broadness is caused by intermolecular dipole-dipole interactions and $D$ strain, which prevents the observation of the hyperfine interaction with the $\mathrm{Mn}$ nuclei $(I=5 / 2) \cdot{ }^{42}$ The large deviation from $g=2$ of the main spectral feature indicates the influence of the zero-field splitting. The simplicity of the spectrum suggests a large degree of rhombicity $(E / D \approx 1 / 3) .{ }^{43}$ The intensity of the spectra increases upon cooling, while their shape remains unchanged (Figures S5 and S6). The EPR spectra of compounds 3 and 4 exhibit a much higher degree of complexity, featuring three main resonances centred at $g \approx 6.7, g=4.45 / 4.32$ (the strongest one) and 2.06/2.11 which indicates a smaller degree of rhombicity contributions ( $E / D<1 / 3$ Figures S11, S12, S14 and S15). In both cases, the overall intensity increases with cooling while the relative peak intensities remain practically unchanged in the whole temperature range. Interestingly, despite the similar coordination environment (a $\mathrm{C}_{3}$ ligand field), the spectra and the zero-field splitting of compound $\mathbf{1}$ differ significantly from those observed for 3 and 4 . The similarity of the latter is expected, while the differences with 1 could be due to a different ligand field of the donors or to dissimilarity in coordination spheres.

The magnetic behaviour of dinuclear compound $\mathbf{5}$ is analogous to that of the mononuclear species. The measured $X_{\mathrm{M}} T$ product at $300 \mathrm{~K}\left(8.42 \mathrm{~cm}^{3} \mathrm{~K} \mathrm{~mol}^{-1}\right)$ is only slightly below the theoretical value of $8.75 \mathrm{~cm}^{3} \mathrm{~K} \mathrm{~mol}^{-1}$ ( $g=2.0$ and $S=5 / 2$ ) for two noninteracting high-spin $\mathrm{Mn}(\mathrm{II})$ ions in the structure. As described above, near $250 \mathrm{~K}$, the value of the $X_{\mathrm{M}} T$ product is more coincident with the expected one; $9.11 \mathrm{~cm}^{3} \mathrm{~K} \mathrm{~mol}^{-1}$. The higher temperature observations are caused by the extreme sensitivity of the sample, which leads to a minor degree of decomposition inside the instrument. The slight positive slope below $250 \mathrm{~K}$ is ascribed to the same causes as for the mononuclear compounds, whereas the pronounced drop below near $8 \mathrm{~K}$ is a consequence of the zero-field splitting (Figure S16). The reduced magnetization at $2 \mathrm{~K}$ confirms indeed the $S=5 / 2$ spin states of the $\mathrm{Mn}(\mathrm{II})$ centers of $\mathbf{5}$, subject to a small degree of zero field splitting $\left(M / N \mu_{B}=9.16\right.$ at $\left.5 \mathrm{~T}\right)$. X-band EPR spectra at $185 \mathrm{~K}$ on a powdered sample shows several strong resonances, the most important ones centred at $g=2.01, g=2.57, g=3.18$, $g=4.4$ and $g=8$, some of which change their relative intensities with varying temperature. The ensemble is consistent with the presence of zero-field splitting with a high axial character.

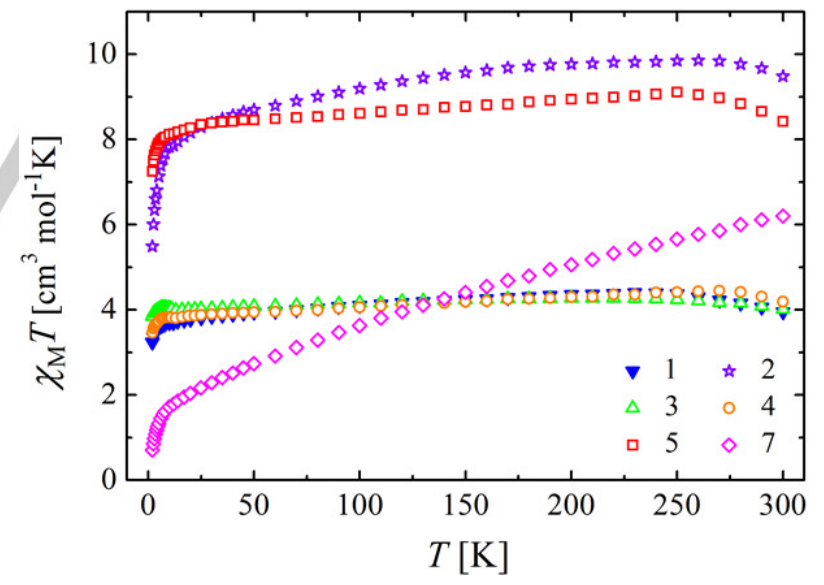

Figure 9. $X_{\mathrm{M}} T$ vs $T$ curves of compounds 1-5 and 7. Measurement setup: $2 \rightarrow 300 \mathrm{~K}, B=0.3 \mathrm{~T}(0.5 \mathrm{~T}$ in the case of 7$)$

Dinuclear systems with short $\mathrm{Mn} \cdots \mathrm{Mn}$ distances (compounds 2, 6 and 7) display different magnetic properties as a result of the coupling between spin magnetic moments. Compound $\mathbf{6}$ displays the typical behaviour of a dinuclear complex with antiferromagnetic interactions between both manganese(II) centres. The $X_{\mathrm{M}} T$ value at $300 \mathrm{~K}$ is significantly lower than expected for two non-interacting high-spin $\mathrm{Mn}(\mathrm{II})$ ions 
(measured of $4.20 \mathrm{~cm}^{3} \mathrm{~K} \mathrm{~mol}^{-1}$ compared with the expected value of $8.75 \mathrm{~cm}^{3} \mathrm{~K} \mathrm{~mol}^{-1}$ for $g=2.0$ and $S=5 / 2$ ). Additionally, a pronounced decrease of the $X_{\mathrm{M}} T$ product upon lowering the temperature is observed, reaching a plateau of $0.1 \mathrm{~cm}^{3} \mathrm{~K} \mathrm{~mol}^{-1}$ of $20 \mathrm{~K}$ (Figure 10, S19). The small magnetic response below this temperature is caused by a trace amount of paramagnetic impurity, made evident on the $X_{\mathrm{M}}$ vs $T$ plot, which exhibits a sharp increase below $15 \mathrm{~K}$ (Figure S22). The data of the $X_{\mathrm{M}}$ vs $T$ plot were fit using the program $\mathrm{PHI}^{44}$ by matrix diagonalization of the isotropic spin Hamiltonian defined in equation 1:

$$
\widehat{H}=-2 J\left(\hat{S}_{1} \hat{S}_{2}\right)+g \mu_{B} B \hat{S}
$$

where $J$ is the exchange constant, $\widehat{S}$ is total spin operator, $\widehat{S_{1}}=$ $\widehat{S_{2}}=5 / 2$ are the spin operators of the individual $\mathrm{Mn}(\mathrm{II})$ ions, $B$ is the magnetic induction and $\mu_{B}$ is the Bohr magneton. A simultaneous fit of the magnetization and the molar susceptibility data using a fixed $g$ factor $(g=2.05)$, yielded the exchange constant $J=-24.18 \mathrm{~cm}^{-1}$ and $0.9 \%$ of paramagnetic impurity $(S=5 / 2)$. As it can be seen from Figure 10 , the proposed model slightly overestimates the $X_{\mathrm{M}} T$ product in the temperature region of $50-200 \mathrm{~K}$. Thus, additional fits on a restricted dataset corresponding to the temperatures below 200 $\mathrm{K}$ led to a slightly more negative coupling; $J=-25.10 \mathrm{~cm}^{-1}$ (Figure S22). ${ }^{45}$

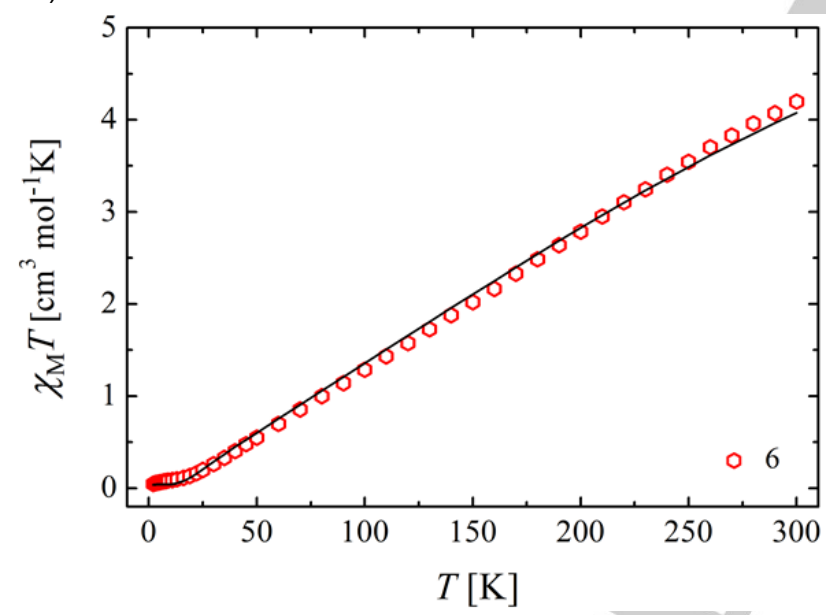

Figure 10. $X_{M} T$ vs $T$ curve of compound 6. Measurement setup: $2 \rightarrow 300 \mathrm{~K}$, $B=0.3 \mathrm{~T}$. Solid line represents the results of the fit.

$$
1 \text { exchange co }
$$

Minor temperature variations of the exchange constant have already been reported for an antiferromagnetically coupled $\mathrm{Mn}$ (II) dimer and it was rationalised as the consequence of small changes in the bridging geometry and the lattice expansion upon warming. ${ }^{46}$ In any case, the observed intensity of the exchange coupling is one order of magnitude higher than reported for compounds containing the $\left\{\mathrm{Mn}_{2}\left(\mu_{2}-\mathrm{O}\right)_{2}\right\}$ unit with tetrahedral coordination environment around metal ion (Table S6). ${ }^{47}$ This could be rationalised in terms of the comparatively shorter Mn $\cdots M n$ distance (3.1447(4) $\AA$ ) and more acute Mn-O-
Mn bridging angles (average $95.36^{\circ}$ ), which provide a more efficient pathway for the superexchange interaction mechanism involving $3 d$ orbitals of metal ion and p-orbitals of alkoxy oxygen atoms from the ligand, and perhaps some higher degree of direct overlap. However, the value of $J$ obtained for compound $\mathbf{6}$ is lower than those reported for dialkyl or diamido bridged Mn(II) dimers (Table S6). 19,25,46,48

The variable temperature EPR spectra of $\mathbf{6}$ mirror remarkably well the reported magnetic data. The intensities of most spectral features (with major resonances at $g=3.35,2.48,1.77$ and 1.43) decline systematically in lowering the temperature while the intensity of transitions at $g=4.96$ and $g=2.20$ initially increase $(100-280 \mathrm{~K})$ before disappearing at the lowest temperatures. As a result, the EPR response at $4 \mathrm{~K}$ is silent as expected for an $S=0$ ground state of the dimer (Figures 11, S20, S21). At high temperatures ( $198 \mathrm{~K}$ and $280 \mathrm{~K})$, the spectral pattern is quite complex, with numerous features in the almost entire range explored ( 500 to $5500 \mathrm{G}$ ). The Boltzmann factors of the energy levels, as extracted from the $J$ value indicate that there is a significant population of spin states from $S=0$ to $S=4$ at these temperatures, justifying a rich structure of the spectra. Upon cooling to the $100-130 \mathrm{~K}$ range, the dominant contributions arise from transitions related to the spin states $S=1$ and $S=2$, while below $70 \mathrm{~K}$, significant features arise only from the population of the $S=1$ energy level (Figure $S 21$ ).

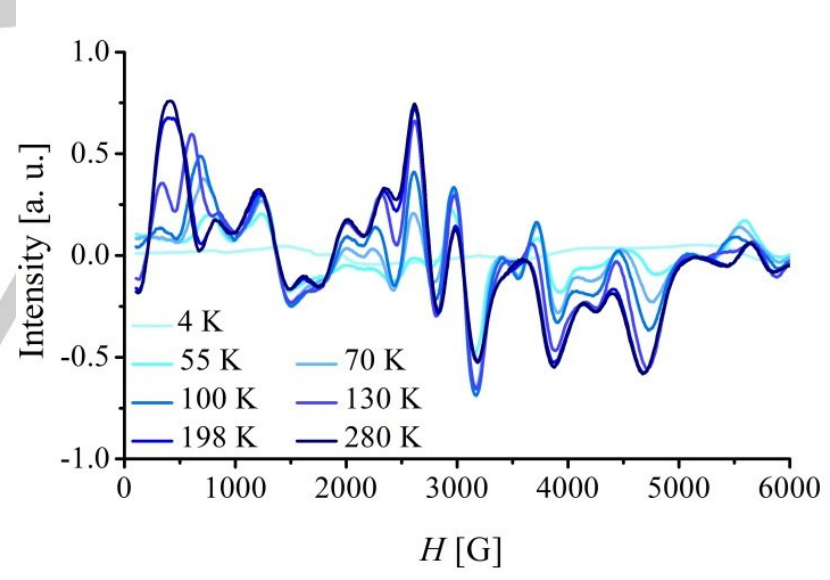

Figure 11. Variable temperature (4-280 K) $X$-band EPR spectra $(f=9.422$ $\mathrm{GHz}$ ) of powdered sample of compound 6 .

The $X_{M} T$ vs $T$ plot for compound 2 shows a value of $X_{M} T$ at 300 $\mathrm{K}\left(9.48 \mathrm{~cm}^{3} \mathrm{~K} \mathrm{~mol}^{-1}, g=2.08\right)$ that lies only just above the theoretical value of $8.75 \mathrm{~cm}^{3} \mathrm{~K} \mathrm{~mol}^{-1}(g=2.0$ and $S=5 / 2)$ for two non-interacting high-spin $\mathrm{Mn}(\mathrm{II})$ ions. As seen for complexes 1, 3 and 4, a smooth maximum is seen near $260 \mathrm{~K}\left(9.86 \mathrm{~cm}^{3} \mathrm{~K}\right.$ $\mathrm{mol}^{-1}$ ), as a consequence of the slight degradation of the sample above that temperature. Below this point, the positive slope is only perceptible from near $160 \mathrm{~K}$, whereas for temperatures close to $15 \mathrm{~K}$, the decline becomes much sharper (Figure S7). These results indicate that the behaviour of 
complex $\mathbf{2}$ is more similar to that of the complexes with isolated $\mathrm{Mn}$ (II) centers than to the structurally related cluster $\mathbf{6}$. Thus, the effect of the magnetic coupling between the Mn centres that could be anticipated only manifests itself very slightly by the small positive slope below $160 \mathrm{~K}$, in sharp contrast to the effect seen for 6 (Figure 10). Consistent with this, the reduced magnetization measurements at $2 \mathrm{~K}$ easily saturates to the expected value for two independent $\mathrm{Mn}(\mathrm{II})$ centers $\left(\mathrm{M} / \mathrm{N} \mu_{B}\right.$ $=9.14$ at $5 \mathrm{~T}$; expected value, $M / N \mu_{B}=10$ ). The temperature dependent X-band EPR spectra are in agreement with the SQUID measurements and resemble these for compound 1 for a highly rhombic system. The main difference is an additional feature at $g=2.00$ that decays and becomes barely detectable below $130 \mathrm{~K}$. Since the temperature evolution of the spectra as well as that of $X_{\mathrm{M}} T$, are rather complex and cannot be explained with a simple coupling model, even taking into account only zero-field splitting effects, the possibility of a thermal equilibrium between different spin states $(S=5 / 2, S=3 / 2, S=1 / 2)$ exists, as has been invoked before. ${ }^{12 \mathrm{e}, 40}$ The lack of significant coupling indicates that a super-exchange mechanism through bridging $s p^{3}$ carbon atoms is not effective. This is caused by the long $\mathrm{Mn}-\mathrm{C}$ bond distances within the asymmetric $\left\{\mathrm{Mn}_{2}\left(\mu_{2^{-}}\right.\right.$ C) ${ }_{2}$ \} core (especially that of $2.488(3) \AA ; 0.12 \AA$ above the sum of covalent radii of two atoms ${ }^{49}$ ), which keep both $\mathrm{Mn}$ (II) centers disconnected magnetically. The peculiar local 'hypercoordination' geometry around the bridging carbon atoms may also contribute to its inefficient exchange interaction. ${ }^{50}$ Conversely, compound 7 displays a behaviour closer to that of compound 6, resulting from antiferromagnetic interactions between $\mathrm{Mn}(\mathrm{II})$ ions. At room temperature $(300 \mathrm{~K})$, the $X_{\mathrm{M}} T$ value $\left(6.20 \mathrm{~cm}^{3} \mathrm{~K} \mathrm{~mol}^{-1}\right)$ is below than expected for two noninteracting high-spin $\mathrm{Mn}(\mathrm{II})$ ions $\left(8.75 \mathrm{~cm}^{3} \mathrm{~K} \mathrm{~mol}^{-1}\right.$ for $g=2.0$ and $S=5 / 2$ ). By lowering the temperature, an almost linear decrease of $X_{\mathrm{M}} T$ is observed followed by a sharp decline below $12 \mathrm{~K}$ (Figure 9, S23). The non-zero $X_{\mathrm{M}} T$ product at $2 \mathrm{~K}(0.71$ $\left.\mathrm{cm}^{3} \mathrm{~K} \mathrm{~mol}^{-1}\right)$ indicates the presence of paramagnetic impurities, which prevents fitting the data for a precise determination of $J$. However, the significantly larger coupling inferred from the data in comparison with compound $\mathbf{2}$ arises from shorter $\mathrm{Mn}-\mathrm{C}$ bonds (2.214 and $2.419 \AA$ (7) vs 2.235 and $2.489 \AA$ for 2) and also importantly, a lower degree of 'hypercoordination' which influences the directionality of the overlap and enables a better pathway for the superexchange interaction mechanism between $\mathrm{Mn}(\mathrm{II})$ ions. ${ }^{51}$

\section{Conclusions}

This study uncovers the diversity of alkali-metal triorganomanganate structures, ranging from simple monomeric motifs to intricate supramolecular networks. Co-complexation approach of the single-metal reagents $\mathrm{Mn}\left(\mathrm{CH}_{2} \mathrm{SiMe}_{3}\right)_{2}$ and $\mathrm{M}\left(\mathrm{CH}_{2} \mathrm{SiMe}_{3}\right) \quad(\mathrm{M}=\mathrm{Na}, \mathrm{K})$ in hexane/benzene solutions produced the alkali-metal triorganomanganates $\left[\left\{\mathrm{NaMn}\left(\mathrm{CH}_{2} \mathrm{SiMe}_{3}\right)_{3}\right\}_{\infty}\right](1)$ and $\left[\left\{\mathrm{KMn}\left(\mathrm{CH}_{2} \mathrm{SiMe}_{3}\right)_{3} \cdot \mathrm{C}_{6} \mathrm{H}_{6}\right\}_{2}\right](2) . \mathrm{X}$ - ray crystallographic studies have revealed the structural variations of this heterobimetallic species, showing an important alkali-metal effect. Thus while $\mathrm{K}$ congener $\mathbf{2}$ displays a discrete dimeric structure, where the alkali-metal is stabilized by $\pi$-engaging with a molecule of benzene, unsolvated sodium magnesiate 1 forms a much more complex 2D network, made up exclusively by a combination of electron deficient bonds $\mathrm{Na}-$ $\mathrm{C}$ and $\mathrm{Mn}-\mathrm{C}$ bonds in which the $\mathrm{C}$ atoms are pentacoordinated. Addition of Lewis donors TMEDA, dioxane (4 equivalents) and $\mathrm{DABCO}$ cause the deaggregation of the intricate structure of 1 to give monomeric [(TMEDA $)_{2} \mathrm{NaMn}\left(\mathrm{CH}_{2} \mathrm{SiMe}_{3}\right)_{3}$ ] (3), dimeric $\left.\left[\left\{\mathrm{NaMn}\left(\mathrm{CH}_{2} \mathrm{SiMe}_{3}\right)_{3}\right\}_{2} \text { (dioxane }\right)_{7}\right]$ (5) and polymeric $\left[\left\{\mathrm{Na}_{2} \mathrm{Mn}_{2}\left(\mathrm{CH}_{2} \mathrm{SiMe}_{3}\right)_{6}(\mathrm{DABCO})_{2}\right\}_{\infty}\right]$ (7) respectively, with the propagation in $\mathbf{7}$ formed by $\mathrm{Na}-\mathrm{N}_{\mathrm{DABCO}}$ dative bonds. Contrastingly, while adding TMEDA to potassium manganate 2 affords [(TMEDA $\left.)_{2} \mathrm{NaMn}\left(\mathrm{CH}_{2} \mathrm{SiMe}_{3}\right)_{3}\right]$ (4), which is isostructural with its sodium congener $\mathbf{3}$, introducing four equivalents of cyclic ether dioxane affords novel heteroleptic $\left[\left\{(\text { dioxane })_{6} \mathrm{~K}_{2} \mathrm{Mn}_{2}\left(\mathrm{CH}_{2} \mathrm{SiMe}_{3}\right)_{4}\left(\mathrm{O}\left(\mathrm{CH}_{2}\right)_{2} \mathrm{OCH}=\mathrm{CH}_{2}\right)_{2}\right\}_{\infty}\right] \quad$ (6), which displays a trapped alkoxy-vinyl fragment resulting from $\alpha$ manganation/ring-opening of dioxane by 2 . These results reveal a new alkali-metal effect for this family of mixed-metal compounds, showing an enhanced metallating power for potassium manganate 2 over its $\mathrm{Na}$ analog $\mathbf{1}$ (where addition of dioxane only induces deaggregation).

Noticeably, despite the contrasting structures of manganates $\mathbf{1}$, 3, 4 and 5 , all of them share the same $\left\{\mathrm{Mn}\left(\mathrm{CH}_{2} \mathrm{SiMe}_{3}\right)_{3}\right\}$ anchor and exhibit minimal variation in their $\mathrm{Mn}-\mathrm{C}$ bond distances, providing the foundations to these heterobimetallic structures; whereas $\mathrm{Na}$ and $\mathrm{K}$ are affixed to the frameworks via $\mathrm{M}-\mathrm{CH}_{2}$ and $\mathrm{M}-\mathrm{CH}_{3}$ ancillary bonds. Manganates 2 and 7 illustrate two distinct dimeric arrangements for these bimetallic systems, in forming a cyclic 8-atom ring structure containing both $\mu_{2}$ - and $\mu_{3}$-alkyl ligands or alternatively adopting a pseudolinear, tetranuclear $\mathrm{M} \cdots \mathrm{Mn} \cdots \mathrm{Mn} \cdots \mathrm{M}$ arrangement where all the alkyl groups bind to the metals in a $\mu_{2}$-fashion.

Collectively these findings advance understanding of solvent effects and aggregation in ate chemistry, an area that has received little attention in comparison to single-metal systems (e.g. organolithiums), despite the fact that recent reports have highlighted that the overall performance of these reagents can be finely tuned by introducing variable amounts of Lewis donors. Moreover, new light has been shed on the close relationship of structural/magnetic/reactivity aspects of alkali-metal tris(alkyl) manganates, which should contribute towards further development of synthetic applications of this class of organometallic reagents, which have already shown promising applications in stoichiometric and catalytic organic transformations. In particular, it is interesting to note that 'hypercoordination' of bridging $C$ atoms significantly decreases its ability to couple magnetically $\mathrm{Mn}$ (II) centers. 


\section{Experimental Section}

General Procedures. All experiments were carried out using standard Schlenk and glove box techniques under an inert atmosphere of argon. Solvents (hexane, toluene, benzene, diethyl-ether, THF and pentane) were dried by heating to reflux over sodium benzophenone ketyl and distilled under nitrogen prior to use. $N, N, N^{\prime}, N^{\prime}$ tetramethylethylenediamine (TMEDA) and 1,4-dioxane were dried by heating to reflux over calcium hydride, distilled under nitrogen and stored over $4 \AA$ molecular sieves. $\mathrm{Mn}\left(\mathrm{CH}_{2} \mathrm{SiMe}_{3}\right)_{2},{ }^{19} \mathrm{NaCH}_{2} \mathrm{SiMe}_{3}{ }^{15 a, \mathrm{c}}$ and $\mathrm{KCH}_{2} \mathrm{SiMe}_{3}{ }^{15 a, b}$ were prepared according to literature procedures.

Synthesis of $\left[\left\{\mathrm{NaMn}\left(\mathrm{CH}_{2} \mathrm{SiMe}_{3}\right)_{3}\right\}_{\infty}\right]$ (1) $\mathrm{Mn}\left(\mathrm{CH}_{2} \mathrm{SiMe}_{3}\right)_{2}(0.23 \mathrm{~g}, 1$ $\mathrm{mmol}$ ) and $\mathrm{NaCH}_{2} \mathrm{SiMe}_{3}(0.11 \mathrm{~g}, 1 \mathrm{mmol})$ were suspended together in $10 \mathrm{~mL}$ of hexane followed by $3 \mathrm{~mL}$ of toluene in order to solubilize the product. The brown fine suspension obtained was stirred for $30 \mathrm{~min}$ at room temperature and gently heated in order to obtain a solution. Slow cooling to room temperature afforded $\mathrm{X}$-ray quality crystals. The mixture was then kept overnight at $-34{ }^{\circ} \mathrm{C}$ to yield a crop of needle-like, colorless crystals $(0.23 \mathrm{~g}, 68 \%)$. Anal. Calcd. for $\mathrm{C}_{12} \mathrm{H}_{33} \mathrm{MnNaSi}_{3}$ : C 42.44; H 9.80; N 0.00; found C 42.13; H 9.67; N 0.34 .

Synthesis of $\left[\left\{\mathrm{KMn}\left(\mathrm{CH}_{2} \mathrm{SiMe}_{3}\right)_{3} \cdot \mathrm{C}_{6} \mathrm{H}_{6}\right\}_{2}\right](2) \mathrm{Mn}\left(\mathrm{CH}_{2} \mathrm{SiMe}_{3}\right)_{2}(0.23 \mathrm{~g}, 1$ $\mathrm{mmol})$ and $\mathrm{KCH}_{2} \mathrm{SiMe}_{3}(0.13 \mathrm{~g}, 1 \mathrm{mmol})$ were suspended together in 10 $\mathrm{mL}$ of hexane followed by $3 \mathrm{~mL}$ of benzene in order to solubilize the product. The brown fine suspension obtained was stirred for $30 \mathrm{~min}$ at room temperature and gently heated in order to obtain a solution. Slow cooling to room temperature followed by overnight storage at $-27{ }^{\circ} \mathrm{C}$ afforded orange, needle-like X-ray quality crystals $(0.29 \mathrm{~g}, 67 \%)$. It should be noted that the two coordinated benzene molecules are lost upon drying in vacuo. Anal. Calcd. for $\mathrm{C}_{36} \mathrm{H}_{78} \mathrm{Mn}_{2} \mathrm{~K}_{2} \mathrm{Si}_{6}$ : C $40.52 ; \mathrm{H} 9.35$; N 0.00; found C 40.17; H 9.20; N 0.00 .

Synthesis of [(TMEDA $\left.)_{2} \mathrm{NaMn}\left(\mathrm{CH}_{2} \mathrm{SiMe}_{3}\right)_{3}\right]$ (3) To a solution of in situ formed compound $1(1 \mathrm{mmol})$ in hexane $(7 \mathrm{~mL})$, freshly distilled distilled $N, N, N^{\prime}, N^{\prime}$-tetramethylethylenediamine (TMEDA) $(0.3 \mathrm{~mL}, 2 \mathrm{mmol})$ was added, affording an orange suspension that was left stirring for $30 \mathrm{~min}$ at room temperature. The suspension was then filtered giving an orange solution that was left at room temperature for 24 hours to obtain colorless X-ray quality crystals $(0.37 \mathrm{~g}, 65 \%)$. Anal. Calcd. for $\mathrm{C}_{24} \mathrm{H}_{65} \mathrm{MnNaN}_{4} \mathrm{Si}_{3}$ : C 50.40, H 11. 45; N 9.80; found C 50.07 H $11.09 \mathrm{~N}$ 10.42

Synthesis of [(TMEDA $\left.)_{2} \mathrm{KMn}\left(\mathrm{CH}_{2} \mathrm{SiMe}_{3}\right)_{3}\right]$ (4) To a solution of in situ formed compound $2(1 \mathrm{mmol})$ in a hexane $(7 \mathrm{~mL}) /$ benzene $(2 \mathrm{~mL})$ mixture, freshly distilled $N, N, N$, $N$ '-tetramethylethylenediamine (TMEDA) $(0.3 \mathrm{~mL}, 2 \mathrm{mmol})$ was added, affording an orange suspension that was left stirring for $30 \mathrm{~min}$ at room temperature. The suspension was heated and then filtered while hot, giving an orange solution that was left at room temperature for 24 hours to obtain orange $\mathrm{X}$-ray quality crystals $(0.40 \mathrm{~g}, 68 \%)$. Anal. Calcd. for $\mathrm{C}_{24} \mathrm{H}_{65} \mathrm{KMnN}_{4} \mathrm{Si}_{3}: \mathrm{C} 49.02, \mathrm{H} 11.14, \mathrm{~N}$ 9.53; found C 48.55, H 11.45, N 9.75.

Synthesis $\left.\left[\left\{\mathrm{NaMn}\left(\mathrm{CH}_{2} \mathrm{SiMe}_{3}\right)_{3}\right\}_{2} \text { (dioxane }\right)_{7}\right](5)$ To a solution of in situ formed compound $1(1 \mathrm{mmol})$ in hexane $(5 \mathrm{~mL})$, freshly distilled $1,4-$ dioxane $(0.34 \mathrm{~mL}, 4 \mathrm{mmol})$ was added, affording an orange suspension that was left stirring for $30 \mathrm{~min}$ at room temperature. The suspension was gently heated to obtain an orange solution which upon slow cooling to room temperature afforded colorless X-ray quality crystals $(0.34 \mathrm{~g}$, $52 \%$ ). Anal. Calcd. for $\mathrm{C}_{36} \mathrm{H}_{90} \mathrm{Mn}_{2} \mathrm{Na}_{2} \mathrm{O}_{6} \mathrm{Si}_{6}$ : C, 45.83; $\mathrm{H}, 9.62 ; \mathrm{N}, 0.00$; found $\mathrm{C}, 45.49 ; \mathrm{H}, 9.58 ; \mathrm{N}, 0.00$.
Synthesis of $\left[\left\{(\text { dioxane })_{6} \mathrm{~K}_{2} \mathrm{Mn}_{2}\left(\mathrm{CH}_{2} \mathrm{SiMe}_{3}\right)_{4}\left(\mathrm{O}\left(\mathrm{CH}_{2}\right)_{2} \mathrm{OCH}=\mathrm{CH}_{2}\right)_{2}\right\}_{\infty}\right]$ (6) To a solution of in situ formed compound $\mathbf{1}(1 \mathrm{mmol})$ in a hexane (10 $\mathrm{mL}) /$ benzene $(5 \mathrm{~mL})$ mixture, freshly distilled 1,4-dioxane $(0.34 \mathrm{~mL}, 4$ $\mathrm{mmol}$ ) was added, affording an orange suspension that was left stirring for $30 \mathrm{~min}$ at room temperature. The suspension was gently heated to obtain an orange solution which upon slow cooling to room temperature afforded colorless $X$-ray quality crystals $(0.28 \mathrm{~g}, 53 \%)$. Anal. Calcd. for $\mathrm{C}_{32} \mathrm{H}_{74} \mathrm{~K}_{2} \mathrm{Mn}_{2} \mathrm{O}_{8} \mathrm{Si}_{4}$ : C, 43.31; $\mathrm{H}, 8.41 ; \mathrm{N}, 0.00$; found $\mathrm{C}, 42.42 ; \mathrm{H}, 8.81$; $\mathrm{N}, 0.00$

Synthesis of $\left[\left\{\mathrm{Na}_{2} \mathrm{Mn}_{2}\left(\mathrm{CH}_{2} \mathrm{SiMe}_{3}\right)_{6}(\mathrm{DABCO})_{2}\right\}_{\infty}\right]$ (7) $\mathrm{Mn}\left(\mathrm{CH}_{2} \mathrm{SiMe}_{3}\right)_{2}$ $(0.23 \mathrm{~g}, 1 \mathrm{mmol})$ and $\mathrm{NaCH}_{2} \mathrm{SiMe}_{3}(0.11 \mathrm{~g}, 1 \mathrm{mmol})$ were suspended in $10 \mathrm{~mL}$ of hexane and stirred at room temperature for $30 \mathrm{~min}$. To this suspension DABCO $(0.11 \mathrm{~g}, 1 \mathrm{mmol})$ was added via solid addition tube and the suspension was left stiring for another $30 \mathrm{~min}$ at room temperature. The solvent was exchanged in vacuo for $15 \mathrm{~mL}$ of toluene and the obtained brown suspension was vigorously heated in order to obtain a solution. Slow cooling to room temperature afforded colorless X-ray quality crystals $(0.18 \mathrm{~g}, 40 \%)$. Anal. Calcd. for $\mathrm{C}_{18} \mathrm{H}_{45} \mathrm{MnN}_{2} \mathrm{NaSi}_{3}$ : C, 47.86; H, 10.04; N, 6.20; found C, 46.05; H, 9.16; N, 7.11.

\section{Acknowledgements}

We thank the EPSRC, the Royal Society, and the European Research Council (ERC) for their generous sponsorship of this research. We also thank Professor Robert E. Mulvey for his insightful comments and Mr Alexander Clunie for his assistance in the $\mathrm{CHN}$ analysis of highly air and moisture sensitive compounds.

Keywords: manganese - alkali-metal • 'ate chemistry • cooperativity $\cdot$ magnetism

[1] M. Schlosser in Organoalkali Chemistry, in Organometallics in Synthesis: Third Manual (Ed: M. Schlosser), John Wiley \& Sons, Inc., Hoboken, NJ, USA, 2013.

[2] For selected references see: a) P. Knochel, A. Gavryushin, K. Brade, The Chemistry of Organomagnesium Compounds Wiley, Chichester U.K., 2008. b) R. E. Mulvey, Chem. Commun. 2001, 1049-1056. c) R. E. Mulvey, Organometallics 2006, 25, 1060-1075. d) R. E. Mulvey, F. Mongin, M. Uchiyama, Y. Kondo, Angew. Chem. 2007, 119, 38763899; Angew. Chem. Int. Ed. 2007, 46, 3802-3824. e) R. E. Mulvey, Acc. Chem. Res. 2009, 42, 743-755. f) R. E. Mulvey, Dalton. Trans. 2013, 42, 6676-6693.

[3] a) T. Klatt, J. T. Markiewicz, C. Saemann, P. Knochel, J. Org. Chem. 2014, 79, 4253-4269. b) A. Harrison-Marchand, F. Mongin, Chem Rev. 2013, 113, 7470-7562. c) A. Harrison-Marchand, F. Mongin, Chem. Rev. 2013, 113, 7563-7727.

[4] a) A. Krasovskiy, P. Knochel, Angew. Chem. 2004, 116, 3396-3399; Angew. Chem. Int. Ed. 2004, 43, 3333-3336. b) S. H. Wunderlich, C. J. Rohbogner, A. Unsinn, P. Knochel, Org. Process Res. Dev. 2010, 14, 339-345. c) B. Haag, M. Mosrin, H. Ila, V. Malakhov, P. Knochel, Angew. Chem. 2011, 123, 9968-9999; Angew. Chem. Int. Ed. 2011, 50, 9794-9824.

[5] H. Minami, T. Saito, C. Wang, M. Uchiyama, Angew. Chem. 2015, 127, 4748-4751; Angew. Chem. Int. Ed. 2015, 54, 4665-4668.

[6] a) A. R. Kennedy, J. Klett, R. E. Mulvey, D. S. Wright, Science 2009, 326, 706-708. b) S. E. Baillie, V. L. Blair, D. C. Blakemore, D. Hay, A 
R. Kennedy, D. C. Pryde, E. Hevia, E. Chem. Commun. 2012, 48, 1985-1987. c) W. Clegg, S. H. Dale, E. Hevia, L. M. Hogg, G. W. Honeyman, R. E. Mulvey, C. T. O'Hara, L. Russo, Angew. Chem. 2008, 120, 743-746; Angew. Chem. Int. Ed. 2008, 47, 731-734. d) W. Clegg, B. Conway, D. V. Graham, E. Hevia, A. R. Kennedy, R. E. Mulvey, L. Russo, D. S. Wright, Chem. Eur. J. 2009, 15, 7074-7082.

[7] A. J. Martínez-Martínez, A. R. Kennedy, R. E. Mulvey, C. T. O'Hara, Science 2014, 346, 834-837.

[8] a) S. H. Wunderlich, M. Kienle, P. Knochel, Angew. Chem. 2009, 121, 7392-7396; Angew. Chem. Int. Ed. 2009, 48, 7256-7260. b) R. A. Layfield, Chem. Soc. Rev. 2008, 37, 1098-1107. c) J. M. Concellón, H. Rodríguez-Solla, V. del Amo, Chem. Eur. J. 2008, 14, 10184-10191. d) M. Uchiyama, Y. Matsumoto, S. Nakamura, T. Ohwada, N. Kobayashi, N. Yamashita, A. Matsumiya, T. Sakamoto, J. Am. Chem. Soc. 2004, 126, 8755 .

[9] a) G. Cahiez, C. Duplais, J. Buendia, Chem. Rev. 2009, 109, 14341476. b) G. Cahiez, F. Mahuteau-Betzer, Manganese Organometallics for the Chemoselective Synthesis of Polyfunctional Compounds, in Handbook of Functionalized Organometallics: Applications in Synthesis, Vol. 2 (Ed: P. Knochel), Wiley-VCH, Weinheim, 2005, pp. 541-568. c) K. J. Oshima, Organomet. Chem. 1999, 575, 1-20.

[10] a) L. M. Carrella, W. Clegg, D. V. Graham, L. M. Hogg, A. R. Kennedy, J. Klett, R. E. Mulvey, E. Rentschler, L. Russo, Angew. Chem. 2007, 119, 4746-4750; Angew. Chem. Int. Ed. 2007, 46, 4662-4666. b) V. L. Blair, W. Clegg, B. Conway, E. Hevia, A. R. Kennedy, J. Klett, R. E. Mulvey, L. Russo, Chem. Eur. J. 2008, 14, 65-72. c) V. L. Blair, W. Clegg, R. E. Mulvey, L. Russo, Inorg. Chem. 2009, 48, 8863-8870.

[11] D. A. Valyaev, G. Lavigne, N. Lugan, Coord. Chem. Rev. 2015, 308, 191-235.

[12] For selected references see: a) R. J. Morris, G. S. Girolami, J. Am. Chem. Soc. 1988, 110, 6245-6246. b) R. A. Bartlett, M. M. Olmstead, P. P. Power, S. C. Shoner, Organometallics, 1988, 7, 1801-1806. c) R. J. Morris, G. S. Girolami, Organometallics, 1989, 8, 1478-1485. d) G. M. Yee, K. Kowolik, S. Manabe, J. C. Fettinger, L. A. Berben, Chem. Commun. 2011, 47, 11680-11682. e) R. A. Layfield, S. M. Humphrey, Angew. Chem. 2004, 116, 3129-3131; Angew. Chem. Int. Ed. 2004 , 43, 3067-3069. f) V. L. Blair, L. M. Carella, W. Clegg, J. Klett, R. E. Mulvey, E. Rentschler, L. Russo, Chem. Eur. J. 2009, 15, 856-863. g) J. García-Álvarez, A. R. Kennedy, J. Klett, R. E. Mulvey, Angew. Chem. 2007, 119, 1123-1126; Angew. Chem. Int. Ed. 2007, 46, 11051108.

[13] a) S. E. Baillie, W. Clegg, P. García-Álvarez, E. Hevia, A. R. Kenndy, J. Klett, L. Russo, Chem. Commun. 2011, 47, 388-390. b) D. R. Armstrong, E. M. Brammer, T. Cadenbach, E. Hevia, A. R. Kennedy, Organometallics 2013, 32, 480-489. c) D. R. Armstrong, H. S. Emerson, A. Hernán-Gómez, A. R. Kennedy, E. Hevia, Dalton Trans. 2014, 43, 14229-14238.

[14] R. A. Andersen, E. Carmona-Guzman, J. F. Gibson, G. Wilkinson, J. Chem. Soc., Dalton Trans. 1976, 2204-2211.

[15] a) A. J. Hart, D. H. O'Brien, C. R. Russell, J. Organomet. Chem. 1974, 72, C19-C22. b) B. Conway, D. V. Graham, E. Hevia, A. R. Kennedy, J. Klett, R. E. Mulvey, Chem. Commun. 2008, 2638-2640. c) W. Clegg, B. Conway, A. R. Kennedy, J. Klett, R. E. Mulvey, L. Russo, Eur. J. Inorg. Chem. 2011, 721-726.

[16] a) P. J. Davidson, M. F. Lappert, R. Pearce, Acc. Chem. Res. 1974, 7, 209-217. b) P. J. Davidson, M. F. Lappert, R. Pearce, Chem. Rev. 1976, 76, 219-242.

[17] A. R. Kennedy, J. Klett, R. E. Mulvey, S. D. Robertson, Eur. J. Inorg Chem. 2011, 4675-4679.

[18] A. R. Kennedy, J. Klett, R. E. Mulvey, S. Newton, D. S. Wright, Chem. Commun. 2008, 308-310.
[19] A. Alberola, V. L. Blair, L. M. Carella, W. Clegg, A. R. Kennedy, J. Klett, R. E. Mulvey, S. Newton, E. Rentschler, L. Russo, Organometallics 2009, 28, 2112-2118.

[20] M. S. Kralik, L. Stahl, A. M. Arif, C. E. Strouse, R. D. Ernst, Organometallics 1992, 11, 3617-3621.

[21] These $\mathrm{Mn}-\mathrm{C}$ bond distances are within the same range as those reported for $\left[\left\{\mathrm{Mn}\left(\mathrm{CH}_{2} \mathrm{SiMe}_{3}\right)_{2}\right\}_{\infty}\right]$ where the $\mathrm{Mn}$ atoms also exhibit a distorted tetrahedral $\mathrm{C}_{4}$ geometry, ( $\mathrm{Mn}-\mathrm{C}$ bond lengths ranging from $2.2023(17)$ to $2.4358(17) \AA]$, see reference 19 for details.

[22] The observed values for $\mathrm{K} 1-\mathrm{C} 7$ and $\mathrm{K} 1-\mathrm{C} 15$ (Table 1) are in the same range as those in the homometallic alkyl $\left[\left\{(\mathrm{PMDETA}) \mathrm{K}\left(\mathrm{CH}_{2} \mathrm{SiMe}_{3}\right)\right\}_{\infty}\right]$ $\left(\mathrm{PMDETA}=N, N, N, N^{\prime}, N^{\prime \prime}\right.$-pentamethyldiethylenetriamine; mean K-C, $2.975 \AA$ ] , see reference $15 \mathrm{c}$.

[23] a) G. W. Gokel, S. L. De Wall, E. S. Meadows, Eur. J. Org. Chem. 2000, 2967-2978. b) G. C. Forbes, A. R. Kennedy, R. E. Mulvey, B. A. Roberts, R. B. Rowlings, Organometallics 2002, 21, 5115-5121. c) J. C. Ma, D. A. Dougherty, Chem. Rev. 1997, 97, 1303-1324.

[24] S. Gambarotta, C. Floriani, A. Chiesi-Villa, C. Guastini, J. Chem. Soc., Chem. Commun. 1983, 1128-1129.

[25] R. A. Lewis, S. Morochnik, A. Chapovetsky, G. Wu, T. W. Hayton, Angew. Chem. 2012, 124, 12944-12947; Angew. Chem. Int. Ed. 2012, $51,12772-12775$.

[26] a) K. J. Drewette, K. W. Henderson, A. R. Kennedy, R. E. Mulvey, C. T. O'Hara, R. B. Rowlings, Chem. Commun. 2002, 1176-1177. b) P. C. Andrikopoulos, D. R. Armstrong, A. R. Kennedy, R. E. Mulvey, C. T. O'Hara, R. B. Rowlings, Eur. J. Inorg. Chem. 2003, 3354-3362. c) N. D. R. Barnett, W. Clegg, A. R. Kennedy, R. E. Mulvey, S. Weatherstone, Chem. Commun. 2005, 375-377. d) W. Clegg, S. H. Dale, D. V. Graham, R. W. Harrington, E. Hevia, L. M. Hogg, A. R. Kennedy, R. E. Mulvey, Chem. Commun. 2007, 1641-1643. e) S. E. Baillie, E. Hevia, A. R. Kennedy, R. E. Mulvey, Organometallics 2007, 26, 204-209. f) J. García-Álvarez, D. V. Graham, E. Hevia, A. R. Kennedy, R. E. Mulvey, Dalton Trans. 2008, 1481-1486. g) Y. K. Gun'ko, U. Cristamnn, V. G. Kessler, Eur. J. Inorg. Chem. 2002, 10291031. h) X. He, B. Noll, A. Beatty, R. E. Mulvey, K. W. Henderson, J. Am. Chem. Soc. 2004, 126, 7444-7445. i) K. Merz, S. Block, R. Schoenen, M. Driess, Dalton Trans. 2003, 3365-3369. j) E. Hevia, A. R. Kennedy, R. E. Mulvey, S. Weatherstone, Angew. Chem. 2004, 116, 1741-1744; Angew. Chem. Int. Ed. 2004, 43, 1709-1712. k) M. M. Olmstead, W. J. Grigsby, D. R. Chacon, T. Hascall, P. P. Power, Inorg. Chim. Acta 1996, 251, 273-284. I) S. Sakamoto, T. Imamoto, K. Yamaguchi, Org. Lett. 2001, 3, 1793-1795.

[27] For a seminal review in early examples of s-block ate compounds see: E. Weiss, Angew. Chem. 1993, 105, 1565-1587; Angew. Chem. Int. Ed. 1993, 32, 1501-1670.

[28] S. E. Baillie, T. D. Bluemke, W. Clegg, A. R. Kennedy, J. Klett, L. Russo, M. De Tullio, E. Hevia, Chem. Commun. 2014, 50, 1285912862.

[29] For selected examples see: a) P. C. Andrews, D. R. Armstrong, D. R.; Baker, R. E. Mulvey, W. Clegg, L. Horsburgh, P. A. O'Neil, D. Reed, Organometallics 1995, 14, 427-439. b) D. M. MacDougall, J. J. Morris, B. C. Noll, K. W. Henderson, Chem. Commun. 2005, 456-458. c) J. J. Morris, B. C. Noll, K. W. Henderson, Chem. Commun. 2007, 5191 5193. d) M. Gartner, H. Görls, M. Westerhausen, Acta Crystallogr. Sect. C, 2007, 63, m2287-m2288. e) A. Jaenschke, J. Paap, U. Behrens, Z. Anorg. Allg. Chem. 2008, 634, 461-469.

[30] For a report on the structural variations of Grignard reagents/dioxane complexes see: J. Langer, S. Krieck, R. Fischer, H. Görls, D. Walther, M. Westerhausen, Organometallics 2009, 28, 5814-5820.

[31] For a review see: A. Maercker, Angew. Chem. 1987, 99, 1002-1019; Angew. Chem. Int. Ed. 1987, 26, 972-989. 
[32] J. Randazzo, J. J. Morris, J. A. Rood, B. C. Noll, K. W. Henderson, Inorg. Chem. Commun. 2008, 11, 1270-1272.

[33] J. A. Rood, B. C. Noll, K. W. Henderson, Inorg. Chem. Commun. 2006, 9, 1129-1132.

[34] J. Garcia-Alvarez, E. Hevia, A. R. Kennedy, J. Klett, R. E. Mulvey, Chem.Commun. 2007, 2402-2404.

[35] R. E. Mulvey, V. L. Blair, W. Clegg, A. R. Kennedy, J. Klett, L. Russo Nature Chem. 2010, 2, 588-591.

[36] Sum of internal angles $\{\mathrm{Na1C} M \mathrm{Mn} 1 \mathrm{C} 1\}$ and $\left\{\mathrm{Mn} 1 \mathrm{C} 5 \mathrm{Mn} 1^{\prime} \mathrm{C} 1^{\prime}\right\}$ are 357.93 and $359.34^{\circ}$ respectively.

[37] a) E. Hevia, K. W. Henderson, A. R. Kennedy, R. E. Mulvey, Organometallics 2006, 25, 1778-1785. b) M.-L. Hsueh, B.-T. Ko, T. Athar, C.-C. Lin, T.-M. Wu, S.-F. Hsu, Organometallics 2006, 25 , 4144-4149. c) S. C. Cole, M. P. Coles, P. B. Hitchcock, Organometallics 2004, 23, 5159-5168. d) D. R. Armstrong, P. GarcíaÁlvarez, A. R. Kennedy, R. E. Mulvey, J. A. Parkinson, Angew. Chem. 2010, 122, 3253-3256; Angew. Chem. Int. Ed. 2010, 49, 3185-3188.

[38] P. C. Andrikopoulos, D. R. Armstrong, E. Hevia, A. R. Kennedy, R. E. Mulvey, C. T. O'Hara, Chem. Commun. 2005, 1131-1133.

[39] Change of the magnetic properties was accompanied with the colour change to black. Sample was kept in the glovebox between two measurements, but it was exposed to the atmosphere upon removal from the SQUID after the first experiment.

[40] A. D. Bond, R. A. Layfield, J. A. MacAllister, M. McPartlin, J. M. Rawson, D. S. Wright, Chem. Commun. 2001, 1956-1957.

[41] One of the possible impurities in these systems could be the starting reagent $\mathrm{Mn}\left(\mathrm{CH}_{2} \mathrm{SiMe}_{3}\right)_{2}$. References 14 and 19 reported the magnetic properties of this compound with antiferromagnetic coupling between spin carriers.

[42] C. Duboc, M.-N. Collomb, F. Neese, Appl. Magn. Reson. 2010, 37, 229-245.

[43] C. Duboc, V. Astier-Perret, H. Chen, J. Pécaut, R. H. Crabtree, G. W. Brudvig, M.-N. Collomb, Inorg. Chim. Acta, 2006, 359, 1541-1548.

[44] N. F. Chilton, R. P. Anderson, L. D. Turner, A. Soncini, K. S. Murray, J. Comput. Chem. 2013, 34, 1164-1175.

[45] Simultaneous fit of the magnetization and magnetic susceptibility yielded the value of coupling constant $J=-25.00 \mathrm{~cm}^{-1}$ and $0.9 \%$ of paramagnetic impurity $(S=5 / 2)$ while the fit of only magnetic susceptibility data gave the coupling constant $J=-25.10 \mathrm{~cm}^{-1}$ and $1.2 \%$ of paramagnetic impurity $(S=5 / 2)$.

[46] C. Ni, G. J. Long, F. Grandjean, P. P. Power, Inorg. Chem. 2009, 48, 11594-11600.

[47] a) D. Coucouvanis, K. Greiwe, A. Salifoglou, P. Challen, A. Simopoulos, A. Kostikas, Inorg. Chem. 1988, 27, 593-594. b) J. Chai, H. Zhu, A. C. Stückl, H. W. Roesky, J. Magull, A. Bencini, A. Caneschi, D. Gatteschi, J. Am. Chem. Soc. 2005, 127, 9201-9206. c) S. K. Kondaveeti, S. Vaddypally, C. Lam, D. Hirai, N. Ni, R. J. Cava, M. J. Zdilla, Inorg. Chem. 2012, 51, 10095-10104. d) Y. Mikata, H. So, A. Yamashita, A. Kawamura, M Mikuriya, K. Fukui, A. Ichimura, S. Yano, Dalton Trans. 2007, 3330-3334.

[48] a) P. Crewdson, S. Gambarotta, G. P. A. Yap, L. K. Thompson, Inorg. Chem. 2003, 42, 8579-8584. b) E. Solari, F. Musso, E. Gallo, C. Floriani, Organometallics 1995, 14, 2265-2276.

[49] B. Cordero, V. Gómez, A. E. Platero-Prats, M. Revés, J. Echeverría, E. Cremades, F. Barragán, S. Alvarez, Dalton Trans. 2008, 2832-2838.

[50] "Six coordinate" geometry around the bridging C atom (C11) consists of two hydrogen atoms, a 'closer' and a 'distant' $\mathrm{Mn}$ atom, a Si atom (Si2) and the weakly interacting $\mathrm{K}$ atom.

[51] "Five coordinate" geometry around the bridging $\mathrm{C}$ atom (C5) consists of two hydrogen atoms, a 'closer' and a 'distant' Mn atom and a Si atom (Si2). 


\section{Entry for the Table of Contents}

\section{FULL PAPER}

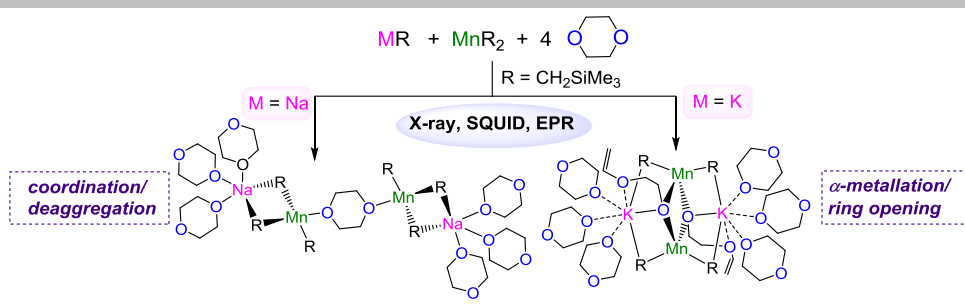

Heavy metal influenced Disclosing intriguing structural/synthetic/magnetic correlations in manganate chemistry, studies on the reactivity of tris(alkyl)manganates $\mathrm{MMnR}_{3}\left(\mathrm{M}=\mathrm{Na}, \mathrm{K} ; \mathrm{R}=\mathrm{CH}_{2} \mathrm{SiMe}_{3}\right)$ towards Lewis bases have revealed that the outcome of these processes is controlled by the alkali-metal present.
Marina Uzelac, Ivana Borilovic, Marco Amores, Thomas Cadenbach, Alan R. Kennedy, Guillem Aromi, ${ }^{*}$ and Eva Hevia*

Page No. - Page No.

Structural and magnetic diversity in alkali-metal manganate chemistry: Evaluating donor and alkali-metal effects in co-complexation processes 